\title{
ANÁlisis COMPARADO DE LOS REGÍMENES DE LAS CONCESIONES MARÍTIMAS Y DE ACUICULTURA
}

[Compared Analysis of the Maritime and Aquaculture Concession Regimes]

\author{
Jessica Fuentes Olmos* \\ Pontificia Universidad Católica de Valparaíso, Chile
}

\begin{abstract}
RESUMEN
Las concesiones marítimas y de acuicultura recaen sobre la misma clase de bienes nacionales de uso público y, sin embargo, están sometidas a regímenes distintos. El artículo analiza los fundamentos de tales diferencias y si ellas cumplen con los parámetros de la igualdad ante la ley y la no discriminación arbitraria en materia económica. Concluye con una propuesta de adecuación de ambos regímenes en aquellas materias en que no se justifica el régimen diferenciado, con el fin de ajustar sus normas a las exigencias constitucionales.
\end{abstract}

Palabras clave

Concesiones - Concesiones marítimas - Concesiones de acuicultura Igualdad ante la ley.

\begin{abstract}
Albeit the maritime and aquaculture concessions are granted for the same kind of public-use, national assets, they are subject to different regimes. This article analyzes the grounds of said differences and whether they meet the parameters of equality before the law and arbitrary non-discrimination in economic matters. It finishes with a proposal for adequacy of both regimes in such matters where the different regime policy is not justified in order to adjust their regulations to the constitutional requirements.

\section{KEYWORDS}

Concessions - Maritime Concessions - Aquaculture Concessions - Equality before the law.
\end{abstract}

RECiBIDo el 30 de octubre y ACEPTADo el 9 de diciembre de 2013

* Profesora de Derecho Constitucional en la Escuela de Derecho de la Pontificia Universidad Católica de Valparaíso. Dirección postal: Bellavista 168, edificio Centenario, piso 18, Valparaíso, Chile. Correo electrónico: jessica.fuentes@ucv.cl 


\section{INTRODUCCIÓN**}

En la actualidad varias actividades económicas requieren el uso y explotación de bienes que pertenecen al denominado dominio público, respecto del cual el Estado tiene la atribución de regular y administrar su uso exclusivo incidiendo, mediante el régimen de asignación que se instaure, en el ejercicio de las actividades económicas que dependen de tales bienes, ya que se interviene en el acceso a ellos. Así se pueden destacar los bienes nacionales de uso público como las playas, el mar, etc., y los recursos naturales respecto de los cuales la Constitución o la ley declaran su calidad de bienes del Estado, como por ejemplo, las minas, la energía geotérmica, etc. En consecuencia, en el presente artículo se utilizará el término bienes para referirse tanto a uno como a otra clase de bienes, en cuanto ellos sean integrantes del denominado dominio público.

Los regímenes concesionales son aplicables por igual a todos los particulares que pretenden la gestión y aprovechamiento del mismo bien. Sin embargo, en el caso de los terrenos de playa, playa, porciones de agua y fondo de mar y rocas y los terrenos de playa fiscales, esto es, aquéllos bienes cuya administración se encuentra bajo la competencia del Ministerio de Defensa Nacional, a través de la Subsecretaría para las Fuerzas Armadas, existen dos regímenes diversos para asignarlos a los particulares, dependiendo de la actividad en la que será utilizado el bien respectivo: el régimen de las concesiones marítimas (régimen general aplicable a cualquier actividad que requiera de estos bienes y que no sea la acuicultura) y el de las concesiones de acuicultura (régimen especial al que se somete la actividad de acuicultura).

El objetivo del presente trabajo es poner de relieve las diferencias entre ambos regímenes para determinar si el estatuto diferenciado puede fundarse constitucionalmente, como asimismo poner de relieve ciertas dudas e inconsistencias que surgen de cada régimen en particular, a la luz de otros derechos constitucionales, particularmente la libertad de acceso a la propiedad y el derecho de propiedad.

En consecuencia, el estudio expondrá en qué consiste el dominio público y

** Abreviaturas: DFL. $\mathrm{N}^{\circ}$ 340, de 1960 = Decreto con fuerza de ley $\mathrm{N}^{\circ}$ 340, de 1960, del Ministerio de Hacienda: Sobre concesiones maritimas; DS. N² 2, de 2005= Decreto supremo $N^{\circ} 2$, de 2005, del Ministerio de Defensa Nacional: Sustituye reglamento sobre concesiones maritimas, fijado por Decreto $\mathrm{N}^{\circ} 660$ (M) de 1988, del Ministerio de Defensa Nacional; LGPA. = Ley general de pesca y acuicultura cuyo texto refundido, coordinado y sistematizado fue fijado por Decreto supremo $\mathrm{N}^{\circ} 430$, de 1991, del Ministerio de Economía, Fomento y Reconstrucción. 
el alcance de las potestades del Estado sobre los bienes que lo componen, y en particular, el objetivo de la técnica concesional. A continuación se analizará la igualdad constitucional como límite para el legislador al momento de crear estatutos de bienes que inciden en actividades económicas amparadas, para culminar con la comparación de los regímenes de las concesiones marítimas y las de acuicultura y las principales conclusiones que pueden derivarse desde una perspectiva constitucional.

\section{CONCEPTO DE DOMINIO PÚBLICO}

\section{Y ATRIBUCIONES DEL ESTADO SOBRE EL MISMO}

El aprovechamiento de las cosas por el hombre ha sido, desde antiguo, objeto de regulación jurídica, desarrollada primeramente en forma más completa desde la perspectiva del derecho privado. El aprovechamiento de las cosas estará determinado tanto por las cualidades propias de cada bien como por el régimen jurídico que le sea aplicable. Cuando se habla del ejercicio de actividades económicas que se basan en el aprovechamiento de ciertos bienes, lo primordial será determinar el régimen jurídico a que se encuentra sometido porque de sus potenciales limitaciones dependerá la mayor o menor posibilidad de desarrollo de la actividad concreta que se trate de realizar, suponiendo que tales limitaciones determinan la mayor o menor libertad que tendrá el concesionario para el aprovechamiento del bien sobre el que recae la concesión o, de los derechos en que ella consiste.

En el mundo moderno, ciertas actividades económicas se basan en la explotación y utilización de recursos naturales: sea por su extracción o consumo directo (minerales, aguas), o por su utilización al constituirse en el sustrato que soporta la instalación de estructuras necesarias para el ejercicio de una actividad (muelles o cañerías en el suelo marino, etc).

Progresivamente y a medida que aumentan los avances de la tecnología aplicada al ejercicio de actividades económicas, ha sido posible la explotación y utilización de un espectro cada vez más amplio de bienes que hacen posible nuevas actividades productivas: la utilización de la energía geotérmica, las exploraciones mineras submarinas, los cultivos de peces en sectores profundos o mar afuera, los complejos portuarios de mayor extensión y tecnología, etc.

Gran parte de esta gama de bienes que se requieren para el ejercicio de estas actividades no se encuentran dentro del tráfico jurídico privado y, por el contrario, se encuentran sometidos a un régimen de derecho público. Precisamente porque al diversificarse y complejizarse las actividades económicas, se diseñan nuevas fórmulas de explotación de recursos que son propuestas al Estado, donde este último resguardando el interés público, mantiene, se dirá por ahora, un poder de supervigilancia sobre tales bienes. 
En este contexto, se abordará en este apartado el denominado dominio público, como ese conjunto de bienes que por naturaleza o por la afectación realizada por un acto de autoridad, está destinado al uso directo del público.

Conforme con el Código Civil, se llaman bienes nacionales aquellos cuyo dominio pertenece a la nación toda. Son bienes nacionales de uso público o bienes públicos si su uso pertenece a todos los habitantes de la nación, como calles, plazas, caminos, mar adyacente y sus playas. Son bienes del Estado o bienes fiscales, si su uso no pertenece generalmente a los habitantes ${ }^{1}$.

A partir de esta distinción, se aplica a tales bienes regímenes diversos, esto es, los bienes nacionales de uso público están sometidos a las normas del derecho público, en tanto, los bienes fiscales están sometidos, en términos generales, a las reglas del derecho privado ${ }^{2}$. La diferencia de régimen da cuenta del diverso vínculo que existe entre cada clase de bienes y el Estado.

En el caso de los bienes nacionales de uso público ha sido la naturaleza o la expresa voluntad del Estado a través de un acto de Autoridad, la ley, lo que ha determinado su destino al uso público; en cambio, los bienes fiscales son aquéllos que el Estado requiere para su funcionamiento, o más precisamente, el de sus órganos, por ende, respecto de tales bienes el Estado actúa como dueño, tal como podría hacerlo un particular respecto de sus propios bienes, teniendo obviamente ciertas características específicas que provienen de las exigencias de la legalidad. Los regímenes concesionales a que se aludirá en el presente trabajo están referidos a los bienes integrantes del denominado dominio público, por lo cual se excluirá el estudio más específico de los bienes fiscales ${ }^{3}$.

El dominio público ha sido entendido de diversas maneras, en cuanto a través de él se pretende describir la relación del Estado con los bienes que forman parte de él, lo que se funda en una específica concepción de lo que corresponde al Estado en torno a dichos bienes y, lo que resulta ser aún más importante, la extensión de su potestad en cuanto los entrega en uso a los particulares.

Siguiendo a Montt Oyarzún, puede ordenarse la evolución del concepto dominio público en la doctrina en torno a las siguientes teorías: el reconocimiento de un poder de policía y vigilancia que el Estado ejerce sobre los bienes del dominio público, sostenida por Víctor Proudhon; un tipo de propiedad cuyas peculiaridades estarían fundadas en su afectación

${ }^{1}$ Artículo 589 CC.

${ }^{2}$ Bermúdez Soto, Jorge, Derecho administrativo general (2a edición, Santiago, Thomson Reuters, 2011), pp. 553-554.

${ }^{3}$ Otros bienes afectos al uso de un órgano público y sometidos al derecho privado (derecho civil), son los bienes municipales, regidos en virtud del artículo 33 de la LOC de Municipalidades. 
a una utilidad pública, defendida por Maurice Hauriou; una potestad para el ejercicio de una función de servicio público que dichos bienes prestan a los intereses generales, lo que es planteado por José Luis Villar Palasí; y, el cumplimiento de deberes a la Administración considerándose el dominio público como una prestación asistencial objetiva, lo que es sostenido por Luciano Parejo Alfonso ${ }^{4}$.

Para efectos de este trabajo se seguirá la teoría del dominio público como prestación asistencial objetivada, sostenida por Luciano Parejo Alfonso, la que no se limita ni fija su atención en la idea de las potestades públicas que pueden ser ejercidas sobre los bienes integrantes del dominio público sino que sostiene la idea de deberes constitucionales y legales que la relación demanial establece para la Administración Pública: "La cosa pública consiste en la relación jurídica en sentido estricto que nace en el momento en que la Administración se autovincula por acto propio a la creación y mantenimiento de una determinada prestación, en aplicación del ordenamiento jurídico que lo prevé y regula asi'"s. El dominio público se concibe así como una prestación asistencial objetivada, esto es, como una causa o justificación que el ordenamiento jurídico recoge a fin de imponer a la Administración la obligación de dar cumplimiento a una serie de deberes y cargas frente a los particulares.

Para Parejo Alfonso la "Administración sirve al interés general para eso se le atribuyen competencias" ${ }^{6}$. El dominio público es algo dinámico y no material ${ }^{7}$ cuya consistencia no viene dada por los bienes que en un momento lo sirven, sino en función de los cometidos propios que el poder público debe cumplir y en los que se expresan las necesidades y las aspiraciones sociales evolutivas. Escribe Parejo Alfonso: "La cosa pública puede ser de dos tipos: aquellas cosas públicas que tienen por objeto la utilización individual, es decir, que una vez creada la cosa pública la Administración va a tener que entablar relaciones jurídicas concretas en el sentido amplio de aprovechamiento con

${ }^{4}$ Montt Oyarzún, Santiago, El dominio público (Santiago, 2002), pp. 103-133.

${ }^{5}$ Parejo Alfonso, Luciano, Dominio público: un ensayo de reconstrucción de su teoría general, Revista de Administración Pública, 3 (Madrid, enero-diciembre 1983) 100-102, p. 2409.

${ }^{6}$ Parejo Alfonso, Luciano, Reconstrucción de una teoria general del dominio público, en Anuario Facultad de Ciencias Jurídicas Universidad de Antofagasta, 7 (Antofagasta, 2001), p. 16.

7 Parejo Alfonso, Luciano, cit. (n. 6), pp. 2406-2407: "La cosa pública tiene ciertamente la finalidad de ser aplicada a substratos reales y extrajurídicos, pero no es ella misma una sustancia o materia. Más bien debe considerarse desligada de representaciones materiales y concebida exclusivamente como una relación específica con la norma jurídica." [...] la cosa pública surge sólo desligada de tales elementos, como una realidad jurídica distinta, cuyo núcleo jurídico radica en la relación de su titular con el ordenamiento jurídico; es, pues, una específica relación jurídica”. 
los usuarios de las cosas, o bien, cosas públicas de utilización general, en el sentido que la creación misma de la cosa pública ya produce el efecto pretendido de satisfacción de la necesidad colectiva, como por ejemplo, abrir un parque público al uso general. Lo característico del dominio público es este deber de la Administración de creación, mantenimiento y puesta a disposición permanentemente en forma continuada a lo largo del tiempo, mientras no se altere el ordenamiento jurídico, de una determinada prestación a los ciudadanos. En las cosas públicas de uso general o común el contenido del deber se agota en ese mantenimiento de la cosa pública. En las de utilización individual o privativo además de ese deber se da la autovinculación de la Administración a un contenido predeterminado de las futuras relaciones jurídicas de utilización individualizada./ El dominio público es, simultáneamente:/ a) Una técnica de atribución de títulos causales de intervención del poder público administrativo./ b) Un régimen jurídico exorbitante para la exención (en lo necesario) del orden jurídico-civil ordinario, a fin de proteger la función pública correspondiente, régimen jurídico que afecta las cosas o los bienes en sentido jurídico-civil instrumentalmente precisos como soporte del ejercicio de la función pública"s.

Los bienes integrantes del dominio público tienen las siguientes características: no son susceptibles de ser adquiridos por prescripción, son inembargables, no son susceptibles de hipotecas y otros gravámenes propios del derecho común', su titularidad es atribuida a la Administración; son indisponibles puesto que no pueden convertirse en objeto de la autonomía de la libertad en el campo contractual por los fines a que dichos bienes

${ }^{8}$ Parejo Alfonso, Luciano, cit. (n. 6), p. 20. Por su parte, Zúñiga Urbina, Francisco, Constitución y dominio público (dominio público de minas y aguas terrestres, en Ius et Praxis, 11 (Talca, 2005) 2, p. 92, expresa: "El administrativista F. Garrido Falla, siguiendo a M. Balbé, señala como elementos del dominio público: un elemento subjetivo que concierne a las entidades de Derecho Público que son titulares del dominio; un elemento objetivo que concierne a las cosas públicas susceptibles de dominio público; un elemento teleológico que concierne a la afectación de bienes como criterio necesario, pero no suficiente del dominio público, que tiene como notas relevantes: a) incomerciabilidad (inalienabilidad, imprescriptibilidad e inembargabilidad), b) publicidad posesoria; c) facultad de deslinde; d) facultad de recuperación de oficio; y e) potestad sancionadora.". Confirma esta posición el repaso histórico que realiza FONT I Llovet, Tomás, La protección del dominio público en la formación del derecho administrativo español: potestad sancionadora y resarcimiento de daños, en Revista de Administración Pública, 123 (Madrid, septiembre-diciembre 1990), p. 18, quien da cuenta de la motivación que ha tenido la autoridad pública para intervenir en el uso y explotación de ciertos bienes (como montes, caminos y puentes) para asegurar su cuidado e integridad por la función a que están destinados y que constituye el origen de la formación del régimen administrativo y la conservación de los bienes públicos.

${ }^{9}$ ZúÑIga Urbina, Francisco, cit. (n. 10), p. 89. 
sirven ${ }^{10}$ y en el caso de los bienes nacionales de uso público, se encuentran fuera del comercio humano ${ }^{11}$. Por su parte, el Tribunal Constitucional se ha referido, en particular, a los bienes nacionales de uso público en diversas sentencias afirmando que los bienes nacionales de uso público son una de las excepciones a la libertad de adquisición de toda clase de bienes y, por ende, no son susceptibles de apropiación. Son bienes sujetos a un especial régimen jurídico que implica que son inalienables, imprescriptibles, no susceptibles de embargos o hipotecas ni de expropiación y son entregados en administración, es decir, para su tuición, conservación y cuidado a distintas autoridades según se trate del dominio público terrestre, marítimo, fluvial y no son disponibles y solo susceptibles de ser entregados en uso privativo mediante un específico título habilitante. En definitiva sobre estos bienes no hay propiedad sino uso ${ }^{12}$.

En consecuencia, el régimen jurídico aplicable a los bienes integrantes del dominio público tiene carácter exorbitante del derecho común con tres componentes: régimen de protección, régimen de uso y régimen de vecindad ${ }^{13}$.

El régimen de protección está destinado a evitar el desmembramiento, la degradación y la usurpación de bienes del dominio público, para lo cual se establece la inalienabilidad de los mismos; también comprende la vigilancia de la conservación del dominio público así como la obligación para la Administración de conservarlo y los mecanismos para impedir los ocupantes sin título ${ }^{14}$.

El régimen de uso dice relación con las reglas que definen la manera por la que los ciudadanos pueden utilizar el dominio público, las que son diferentes si se trata de uso común o privativo, conforme se indicó más arriba. Expresa Bon: "El dominio público es una riqueza colectiva, por lo que la Administración debe asegurar su mejor utilización. Por ejemplo, cuando una empresa ejerce su actividad sobre el dominio público, la autoridad administrativa puede imponer sobre ella obligaciones dirigidas, no solamente a garantizar la conservación del dominio público y la protección del orden público, sino también a satisfacer mejor los intereses del público, de donde surge la posibilidad de dictar verdaderas obligaciones de servicio público, las que deben respetar estas empresas si desean continuar siendo autorizadas para utilizar el dominio público"15.

${ }^{10}$ Ibíd., p. 93.

${ }^{11}$ Tribunal Constitucional, sentencia rol No 260 de 1997, considerando $5^{\circ}$.

${ }^{12}$ Tribunal Constitucional, sentencia rol N ${ }^{\circ} 1281$ de 2009 , considerandos $30^{\circ}$ al $32^{\circ}$.

${ }^{13}$ Bon, Pierre, El dominio público ante el derecho administrativo francés, en Revista Chilena de Derecho, 25 (Santiago, abril-junio 1998) 2, p. 314.

${ }^{14}$ Ibíd., p. 316.

${ }^{15}$ Bon, Pierre, cit. (n. 15), pp. 320-321. 
Respecto del uso, el Tribunal Constitucional, citando la doctrina de Jorge Reyes Riveros y Patricio Aylwin Azócar, diferencia entre el uso común y el privativo. El uso común corresponde en general a todos, es anónimo, temporal y no requiere título alguno, y en general está sometido a tres principios: igualdad, pues todos concurren al uso en igualdad de condiciones; libertad, porque no hay más restricciones que las expresamente establecidas y gratuidad. El uso privativo, en cambio, implica que la autoridad que administra el bien lo entregue, por actos específicos de ocupación, temporalmente, con un fin de interés público y, en general, a título oneroso, a un particular quien puede excluir al resto de las personas que accedan a él. Se trata de un uso exclusivo y excluyente ${ }^{16}$.

El régimen de vecindad comprende las cargas recíprocas que el dominio público y los propietarios privados vecinos soportan por el hecho de la contigüidad ${ }^{17}$. Así puede mencionarse como ejemplo el acceso gratuito a las playas públicas que deben otorgar los predios colindantes vecinos, cuando no existan otras vías públicas que sirvan al efecto y que se fundan especialmente en la calidad de bien nacional de uso público y, por ende, perteneciente al dominio público. Esta materia ha sido tratada en diversas sentencias del Tribunal Constitucional. En el requerimiento interpuesto con ocasión de la impugnación del decreto que establecía el reglamento para la aplicación del artículo 13 del Decreto-ley No 1.939 de 1997 que otorga la competencia al Intendente para fijar las vías de acceso a las playas públicas a través de los predios colindantes y siempre que no existan otras vías de acceso, el Tribunal Constitucional lo estimó inconstitucional por la gratuidad ${ }^{18}$ con que se imponía la medida y, en consecuencia, el daño sin indemnización que debían soportar los titulares de los predios colindantes. Importante de destacar es que pese a dicha conclusión, el Tribunal calificó de limitación y no de privación la regulación que pretendía ser desarrollada mediante el decreto impugnado ${ }^{19}$.

${ }^{16}$ Considerando $33^{\circ}$ de la sentencia rol $\mathrm{N}^{\circ} 1281$, cit. (n. 14). El Tribunal Constitucional se ha referido al uso común y al uso privativo en varias sentencias. A modo ejemplar puede citarse sus sentencias roles $\mathrm{N}^{\circ} 1849$ de $2010, \mathrm{~N}^{\circ} 1863$ de 2010, $\mathrm{N}^{\circ} 1986$ de 2011, No 1992 de 2011, N²069 de 2011.

${ }^{17}$ Bon, Pierre, cit. (n. 15), p. 325.

${ }^{18}$ En cualquier caso la gratuidad venía establecida en el citado artículo 13 del Decreto-ley 1.939 de 1977.

${ }^{19}$ Considerandos $22^{\circ}, 32^{\circ}, 34^{\circ}, 35^{\circ}, 41^{\circ}$ y $42^{\circ}$ de la sentencia del Tribunal Constitucional, rol $\mathrm{N}^{\circ} 245-246$ de 1996 . Una crítica al tratamiento que realiza el Tribunal Constitucional de la limitación y privación en la sentencia rol 245-246 se encuentra en Aldunate Lizana, Eduardo, Limitación y expropiación: Scilla y Caribdis de la dogmática constitucional de la propiedad, en Revista Chilena de Derecho, 33 (Santiago, 2006) 2, pp. 285-303. El autor plantea la necesaria separación, 
En causas más recientes, conocidas a través de recursos de inaplicabilidad interpuestos por los dueños de predios colindantes a playas públicas, en contra de actos específicos del Intendente mediante los cuales se pretendía hacer aplicación de la facultad prevista en el artículo 13 del Decreto-ley N ${ }^{\circ} 1.939$ de 1977, el Tribunal Constitucional ha mantenido su doctrina de estimar la facultad impugnada como la aplicación de una limitación al derecho de propiedad fundada en la función social de la propiedad y ha estimado que la gratuidad a que se refiere la disposición citada, puede ser entendida con referencia a quienes utilizan o se ven beneficiados por las vías de acceso y no necesariamente respecto del Estado que fija las vías, no emitiendo en todo caso un pronunciamiento específico acerca de la constitucionalidad de la gratuidad establecida en la norma mencionada, por no ser un asunto discutido en los juicios con ocasión de los cuales fueron interpuestos los recursos de inaplicabilidad ${ }^{20}$. Interesante resulta destacar que a juicio del Tribunal, en estos casos la función social está dada por la calidad de bienes nacionales de uso público que tienen las playas de mar, las que pueden ser empleadas por quienes acceden a ellas no solo sino también para fines de recreación y de pesca que son los que justifican el establecimiento de las vías de acceso gratuitas previstas en el Decreto-ley $\mathrm{N}^{\circ} 1.939$ de 1977 estimándose, en consecuencia, que al fijar en la norma impugnada solo los fines turísticos o de pesca, el legislador ha limitado y no ampliado el uso que los particulares pueden hace de la playa ${ }^{21}$.

\section{CONCEPTO DE LA CONCESIÓN ADMINISTRATIVA. BIENES SOMETIDOS A REGÍMENES DE CONCESIÓN}

Existen varias definiciones del término concesión. Así puede señalarse que es el "acto de derecho público que confiere a una persona un derecho o un poder que antes no tenía, mediante la transmisión de un derecho o del ejercicio de un poder propio de la Administración, o bien, son actos de concesión los que otorgan a una persona natural o jurídica el derecho de usar

desde la dogmática del derecho de propiedad, entre las categorías de la "limitación" y de la "expropiación". La primera vale delimitación y regulación y la segunda, como intervención concreta que da derecho a indemnización, dejando el problema planteado en el caso de acceso a las playas públicas (la gratuidad por el acceso) como una materia que podría abordarse a través de la igualdad ante las cargas públicas en los casos que las consecuencias económicas sean particularmente gravosas.

${ }^{20}$ Considerandos $20^{\circ}, 23^{\circ}, 24^{\circ} 25^{\circ}, 27^{\circ}$ y $33^{\circ}$ de la sentencia del Tribunal Constitucional, rol $\mathrm{N}^{\circ} 1141$ de 2008 ; y considerandos $31^{\circ}, 37^{\circ}$ y $42^{\circ}$ de la sentencia rol $\mathrm{N}^{\circ} 1215$ de 2009.

${ }^{21}$ Considerando $31^{\circ}$ de la sentencia rol $N^{\circ} 1215$, cit. (n. 22). 
y gozar de algo que pertenece a la Administración, o a prestar en nombre de ella un servicio específico"22.

Cualquiera sea la definición que se utilice, por lo general se señala que la concesión administrativa es un acto administrativo creador de derechos, típicamente administrativos, cuyo otorgamiento se basa en un elenco de poderes de decisión más amplios en manos de la Administración, que podrá conceder o denegar lo solicitado, e incluso condicionar o cargar su ejercicio, según las exigencias de los intereses generales ${ }^{23}$. Se trata de un acto de autoridad unilateral, de imperio, regido por el derecho público y donde el interés perseguido por la Administración es público ${ }^{24}$. La concesión es título constitutivo y garantizador de un derecho a favor de un particular y, también, es el derecho que surge a partir de aquel título ${ }^{25}$. Importante de destacar es que el derecho que nace de la concesión tiene carácter patrimonial y, por ende, está protegido por el derecho de propiedad sobre bienes incorporales de conformidad con el artículo $19 \mathrm{~N}^{\circ} 24 \mathrm{CPol}$.

${ }^{22}$ Sayagués Laso, Enrique, Tratado de Derecho administrativo (Montevideo, 1959), I, p. 420. Una definición que da cuenta del derecho francés señala que "las concesiones de ocupación del dominio público (en contraposición a las concesiones de obras públicas) son las convenciones por las cuales unas personas públicas entregan a otras personas, públicas o privadas, ciertas dependencias del dominio público que dependen de su autoridad, las que estas personas podrán ocupar privativamente, quedando entendido que esta ocupación podrá, en caso necesario, ser una ocupación que implique modificaciones materiales del terreno, es decir, con penetración del subsuelo". Bon, Pierre, El régimen de las concesiones administrativas, en Revista de Derecho Administrativo Económico, 15 (Santiago, julio-diciembre 2005), p. 5.

${ }^{23}$ GARCía PÉrez, Marta, La naturaleza jurídica de la autorización y la concesión, a propósito de la utilización del dominio público, en Anuario de la Facultad de Derecho de la Universidad de La Coruña, 1 (Galicia, 1997), p. 338.

${ }^{24}$ Vergara Blanco, Alejandro, Concesiones de dominio público y caracterización de las concesiones mineras, en Revista Chilena de Derecho, 16 (Santiago, 1989) 3, p. 786.

${ }^{25}$ Cea Egaña, José Luis, Informe en Derecho: Variación del estatuto del dominio sobre concesiones de radiodifusión televisiva, en Revista Chilena de Derecho, 18 (Santiago, 1991) 3, pp. 488; Silva Cimma, Enrique, Derecho administrativo chileno y comparado. Actos, contratos y Bienes (Santiago, Editorial Jurídica de Chile, 1995, reimp. 2001), p. 83. Otro concepto de concesión es el de González Vergara, Ariel, La concesión, acto administrativo creador de Derechos (Santiago, 1965), p. 29, quien señala: "Aquella institución de Derecho público administrativo que tiene la virtud esencial de ampliar la capacidad jurídica de un individuo determinado, esto es, dotarlo de un derecho que antes no tenía, ya sea producto de una traslación de Derechos desde la Administración, ya por el nacimiento ex novo de Derechos en el individuo por disposición del ordenamiento jurídico". Una transcripción de conceptos de concesión de diversos autores en Barbosa Rebolledo, Gonzalo, Concesiones maritimas (seminario de titulación para optar al grado de Licenciado en la Facultad de Ciencias Jurídicas y Sociales de la Universidad de Concepción, Concepción, 1987), pp. 2-5. 
El Tribunal Constitucional ha afirmado acerca de las concesiones administrativas sobre bienes del dominio público:

"TRIGÉSIMO SÉPTIMO: Que la concesión crea una situación juridica compleja que viene conformada por un haz de derechos y obligaciones, debereso cargas perfectamente definidas. Tal delimitación permite sujetar los aprovechamientos y ocupaciones individuales a las superiores exigencias de aquella función y, en general, de los intereses públicos' (Menéndez Pablo, ob. Cit., pág. 249). Los derechos subjetivos que emanan de la concesión tienen tres características que es necesario subrayar./ Por de pronto, son derechos ex novo, pues antes no existian a favor del particular. En este sentido, la concesión constituye derechos. En seguida, los derechos que recaen sobre el bien, tienen una naturaleza real, pues tienen las características propias de éstos, es decir, recaen sobre una cosa, son oponibles a terceros y a la propia administración, aunque ésta pueda imponer cierta precariedad por la revocabilidad que le puede otorgar el ordenamiento juridico. Estos derechos son 'derechos reales administrativos', pues no se rigen por las normas del derecho privado. Estos derechos reconocen que el dominio público está fuera del tráfico jurídico. Por ello, genera un comercio jurídico público. 'No es posible constituir derechos reales privados sobre bienes de dominio público; pero ninguna razón impide la constitución de unos derechos reales - los reales administrativos- sometidos a un régimen especial y que respetan la afectación del dominio público' (González Pérez, Jesús, Los derechos reales administrativos; Edit. Civitas; Madrid, 1989, pág. 22). Estos derechos otorgan a su titular un 'haz de facultades' que puede englobarse en las siguientes: derecho de uso sobre el respectivo bien, que permite su utilización u ocupación; un derecho de goce que permite obtener a su titular todo lo que el bien produce; en algunas ocasiones, otorga el derecho de consumir el bien (por ejemplo, el derecho consuntivo en las aguas, que permite a su titular consumir totalmente el agua en cualquier actividad, sin obligación de restitución); y el de comercio jurídico, que permite al titular incorporar este derecho al tráfico jurídico, bajo ciertas restricciones (González, J., ob. cit., págs. 40 y siguientes). La tercera característica, es que estos derechos son patrimoniales. Ello se traduce en que el derecho sobre la concesión está protegido por el derecho de propiedad; y salvo probibición expresa, legal o de la propia concesión, pueden establecerse respecto de dicho derecho relaciones jurídicas con terceros, sujetas a las condiciones que el derecho imponga"n.

$\mathrm{El}$ acto concesiones da origen a un derecho real administrativo, oponible erga omnes, con la posibilidad de perseguirlo frente a terceros. Sin embargo, no es tan clara la supuesta limitación en el tiempo que algunos le atribuyen,

${ }^{26}$ Sentencia rol $N^{\circ} 1281$, cit. (n. 14). 
puesto que no es predicable respecto de todo tipo de concesión. No es así respecto de las concesiones que recaen sobre minas y aguas, ni tampoco lo era hasta antes de la Ley $\mathrm{N}^{\circ} 20.434$ respecto de las concesiones de acuicultura. Por su parte, la doctrina no está de acuerdo en que sea una característica de la concesión sobre bienes públicos su otorgamiento a título precario, por tratarse de un título que habilita a los particulares para usar en forma particularmente intensa o privativa el dominio público mientras no concurra un interés público prevalente ${ }^{27}$.

Según Vergara Blanco, un elemento común a todo tipo de concesión administrativa, sea de dominio público o de servicio público, es la trasmisión de funciones [sic] desde el ámbito de la Administración Pública al concesionario, por cuanto este último se constituye en un colaborador de la Administración en la explotación del dominio público o la gestión de un servicio público; de allí que surge una relación jurídica duradera entre concesionario y Administración ${ }^{28}$. Sin embargo, esto no es preciso. En el ámbito de las actividades económicas que utilizan bienes nacionales de uso público, como los que son objeto de concesiones marítimas o concesiones de acuicultura, la supuesta "transmisión" de funciones no está referida al ejercicio de actividades empresariales por parte del Estado (la que por lo demás es excepcional conforme al artículo $19 \mathrm{~N}^{\circ} 21 \mathrm{CPol}$.), sino más bien, dicha transmisión está referida a poner a disposición ciertos bienes para su asignación exclusiva a un particular de modo de obtener un mejor aprovechamiento mediante el ejercicio de actividades económicas que el Estado ha decidido promover en el sector privado y no asumir como actividad empresarial del Estado. Por ende, no se trata de una "transmisión” de funciones, ya que el Estado no ejerce, en principio, actividades económicas, sino más bien los particulares concretan una decisión estatal en torno a aprovechar ciertos bienes del dominio público mediante su explotación económica exclusiva para una actividad determinada que se ha decidido promover y que así se constituye en un interés público.

La concesión de dominio público tiene como causa inmediata la explotación rentable de un determinado sector de titularidad administrativa, mediante la incorporación de determinadas instalaciones, de mayor o menor fijeza, dirigidas a una actividad económica que requiere como sede física el

${ }^{27}$ Celaya Bastidas, Rodolfo, Naturaleza juridica del permiso de emisión transable, en Revista Chilena de Derecho, 28 (Santiago, 2002) 2, pp. 341-342.

${ }^{28}$ Vergara Blanco, Alejandro, cit. (n. 26), p. 788. Cea Egaña, José Luis, cit. (n. 27), p. 485: "Tal es, asimismo, el entendimiento de ese concepto por nuestra jurisprudencia, pues la concesión 'crea en favor de un particular una capacidad o un derecho nuevo o transfiere al particular un derecho que es propio de la Administración y del que el particular carecía totalmente' [...]”. 
demanio. El interés general en este caso se concreta en el uso óptimo del dominio público, y se traduce en el poder de intervención sobre este espacio físico, que se manifiesta en la potestad de otorgamiento de los títulos habilitantes y en la intervención administrativa presente a lo largo de toda la explotación. La intervención administrativa proviene de la presencia innegable de un interés público subyacente en toda explotación privativa del dominio público ${ }^{29}$. De otra forma, no se explicaría que aquéllos bienes que se han excluido de la libre apropiabilidad privada, sean luego entregados para su uso exclusivo por un particular.

En efecto, la Constitución establece en su artículo $19 \mathrm{~N}^{\circ} 23$ la libertad para adquirir el dominio de toda clase de bienes, excepto aquellos que la naturaleza ha hecho comunes a todos los hombres o que deban pertenecer a la Nación toda y la ley lo declare así y sin perjuicio de lo dispuesto en otras disposiciones de la misma Constitución (por ejemplo, lo referido al dominio del Estado sobre las minas). Asimismo, la aquélla señala que una ley de quórum calificado y cuando así lo exija el interés general, puede establecer limitaciones o requisitos para la adquisición del dominio de ciertos bienes.

En consecuencia, desde el punto de vista constitucional, la regla general es la apropiabilidad de toda clase de bienes los que están dentro del tráfico jurídico privado y, salvo los que la naturaleza ha hecho comunes a todos los hombres, la publicatio requiere declaración expresa por ley o por la propia Constitución $^{30}$. La posibilidad de uso exclusivo de los bienes que han sido objeto de publicatio por los particulares, se concreta jurídicamente a través la concesión administrativa.

De allí entonces que en la actualidad son bienes susceptibles de concesión las minas ${ }^{31}$, la energía geotérmica ${ }^{32}$, el mar adyacente y sus playas ${ }^{33}$, las aguas terrestres ${ }^{34}$, los bienes nacionales de uso público de la comuna y su subsuelo y los bienes municipales ${ }^{35}$, el espectro radioeléctrico ${ }^{36}$, entre otros.

${ }^{29}$ García Pérez, Marta, cit. (n. 25), p. 343.

${ }^{30}$ Considerandos $34^{\circ}$ y $35^{\circ}$ de la sentencia rol $\mathrm{N}^{\circ} 1281$, cit. (n. 14).

${ }^{31}$ Artículo $19 \mathrm{~N}^{\circ} 24$ CPol.

${ }^{32}$ Artículo $4^{\circ}$ de la Ley $\mathrm{N}^{\circ}$ 19.657: Sobre concesiones de energía geotérmica. Se entiende por energía geotérmica, de conformidad con el artículo 3 de la ley, la que se obtenga del calor natural de la tierra, que puede ser extraída del vapor, agua, gases, excluidos los hidrocarburos, o a través de fluidos inyectados artificialmente para este fin.

${ }^{33}$ DFL. $\mathrm{N}^{\circ} 340$, de 1960.

${ }^{34}$ Artículo 5 CA.

${ }^{35}$ Artículo 5 c) DFL. $N^{\circ} 1$ de 2006, del Ministerio del Interior, que fijó el texto refundido, coordinado y sistematizado de la Ley $\mathrm{N}^{\circ} 18.895$ : orgánica constitucional de Municipalidades.

${ }^{36}$ Artículo 8 Ley $N^{\circ} 18.168$. 


\section{LA IGUALDAD CONSTITUCIONAL COMO LÍMITE AL LEGISLADOR PARA REGULAR LAS CONCESIONES MARÍTIMAS Y DE ACUICULTURA}

Hasta este punto se ha afirmado que los bienes nacionales de uso público suponen una publificación o declaración por ley como tales, de conformidad con el artículo $19 \mathrm{~N}^{\circ} 23 \mathrm{CPol}$,, lo que trae aparejado un régimen excepcional, exorbitante al derecho privado y que se justifica por el interés público al que sirven. De este modo, los bienes nacionales de uso público están fuera del comercio, son inalienables, imprescriptibles, inembargables y no susceptibles de expropiación ${ }^{37}$.

En este contexto, la potestad reguladora del Estado que crea este régimen no se identifica con las facultades de un "dueño", entendiendo por tal, el titular de un derecho de propiedad, sino más bien con la de un administrador que cumple un deber impuesto por la necesidad pública que se desea satisfacer a través de la publificación de tales bienes ${ }^{38}$. De allí entonces que la naturaleza misma del denominado dominio público sea sustantivamente distinta del dominio que determina la relación de los sujetos de derecho privado con las cosas que ingresan a su patrimonio.

Asumiendo dicha diferencia sustantiva entre dominio público y privado por el fin al que cada uno sirve, el régimen a instaurar por el legislador deberá considerar al menos los siguientes aspectos: protección (material y jurídica) de los bienes, vigilancia, conservación, uso y las eventuales cargas públicas ${ }^{39}$ que deberán soportar ciertas categorías de particulares. De esta forma aparecen en términos generales, dos formas de uso, el común y el privativo, creándose los títulos habilitantes, para el ejercicio de este último. Dentro de estos títulos, en lo que interesa a este artículo, están las concesiones administrativas, las que otorgan un derecho real administrativo, de carácter patrimonial protegido por el derecho de propiedad del artículo $19 \mathrm{~N}^{\circ} 24 \mathrm{CPol}$. y que, a diferencia de los bienes del dominio público sobre los que recae tal derecho, sí admiten todo tipo de negociación jurídica (transferencia, constitución de garantías, etc), salvo disposición expresa en contrario.

Especial importancia reviste el interés público que se desea satisfacer cuando se habla de los bienes nacionales de uso público que son objeto de concesiones marítimas y de acuicultura. En ambos casos el uso privativo que habilita dicho título administrativo, consiste en el ejercicio de actividades económicas por particulares. A diferencia de otros bienes que están dentro

\footnotetext{
${ }^{37}$ Sentencia rol 1281, cit. (n. 14).

${ }^{38}$ En los términos utilizados por Luciano Parejo Alfonso se diría, una prestación asistencial objetivada.

${ }^{39}$ En el análisis de Bon denominado régimen de protección, de policía o vigilancia y conservación, uso y de relaciones de vecindad.
} 
del dominio público y que están sometidos a regímenes diferenciados (las minas, las aguas terrestres, la energía geotérmica), acá se está en presencia de dos regímenes diversos pero que recaen sobre la misma categoría de bienes. En consecuencia, este supuesto de hecho que en los otros casos justifica un trato diferenciado, en esta materia debe descartarse. Por este motivo, se ha estimado importante analizar estos diversos regímenes a la luz del principio de igualdad y de la no discriminación arbitraria que se impone a toda autoridad pública, incluido el legislador.

Conforme al artículo $19 \mathrm{~N}^{\circ} 2 \mathrm{CPol}$. se garantiza a todas las personas: "la igualdad ante la ley. En Chile no hay persona ni grupos privilegiados". En la Comisión de Estudios de la Nueva Constitución se planteó la necesidad de completar la garantía que había sido prevista en la Constitución de 1925, en orden a explicitar que no se trataba solo de una garantía de no discriminación arbitraria frente a quien aplica la ley (por ejemplo, el juez o el administrador), sino incluso "contra el legislador" y cualquiera otra autoridad.

De allí que la Constitución establezca en el inciso $2^{\circ}$ del numeral $2^{\circ}$ del artículo 19, la fórmula "ni la ley ni autoridad alguna podrán establecer diferencias arbitrarias". Una diferencia es arbitraria, cuando no es posible distinguir a su respecto un elemento objetivo razonable como criterio fundante del tratamiento diferenciado.

Así el principio de la no discriminación arbitraria puede formularse como "a menos que exista una razón reconocida como relevante y suficiente, según algún criterio identificable y aceptado, ninguna persona puede ser preferida a otra". ${ }^{40}$

De allí se deriva el criterio asumido por la jurisprudencia en cuanto las situaciones iguales deben ser tratadas de la misma manera y que las situaciones desiguales deben ser tratadas en forma distinta ${ }^{41}$, para regular diferentes supuestos de hecho que afectan a grupos humanos diferentes, atendiendo a las particularidades de cada situación concreta, siempre que se basen en aspectos relevantes o razonables. Es el juicio de razonabilidad dentro del cual debe ser entendido el principio de igualdad. "Si el legislador o la autoridadse ven enfrentados a la necesaria diferenciación, ello debe basarse en un criterio de justicia y bien común. De esta forma, todo tratamiento legal diferenciado debe contar con una fundamentación objetiva y razonable, de acuerdo con juicios de valor generalmente aceptados ${ }^{42}$. La igualdad se construye, sobre todo, como

${ }^{40}$ Rabossi, Eduardo, El principio de igualdad y la discriminación, en Revista del Centro de Estudios Constitucionales, 7 (Madrid, 1990), p. 179.

${ }^{41}$ Sentencias rol $N^{\circ} 53$ de 1988 y $203^{\circ}$ de 1994 del Tribunal Constitucional.

${ }^{42}$ Martínez, José Ignacio - ZúÑiga Urbina, Francisco, El principio de razonabilidad en la jurisprudencia del Tribunal Constitucional, en Estudios Constitucionales, 9 (Talca, 2011) 1, pp. 199-226. 
un límite de la actuación de los poderes públicos y como mecanismo de reacción frente a la posible arbitrariedad del poder. Es por tanto, un principio negativo, limitativo, que acota un ámbito de actuación de los poderes públicos" 43 .

En definitiva, no basta el diferente supuesto de hecho para establecer una diferenciación sino que "debe estar basada en una finalidad concreta que la justifique, y todo ello debe ser en sí mismo razonable" ${ }^{\prime 4}$ (prudente, lógico, exento de capricho o irracionalidad). La relación entre estos factores debe caracterizarse además por la proporcionalidad. Esto implica una correspondencia entre el supuesto de hecho y la finalidad. En consecuencia, el legislador puede establecer un trato diferenciado cumpliendo las siguientes condiciones: distinto supuesto de hecho (objetividad de la distinción), finalidad que justifique la distinción, relación entre el supuesto de hecho y la finalidad que cumpla los requisitos de razonabilidad, racionalidad y proporcionalidad ${ }^{45}$.

El Tribunal Constitucional ha establecido como elementos para evaluar si se da cumplimiento al mandato de la igualdad ante la ley y la no discriminación arbitraria ciertos criterios: el elemento diferenciador debe ser objetivo y no fundarse en un propósito de hostilidad o importar un favor o privilegio personal indebido; la finalidad debe ser lícita y sus consecuencias proporcionadas; el trato diverso debe ser razonablemente adecuado y necesario para alcanzar el fin lo que implica realizar un examen de proporcionalidad en sentido estricto, considerando la finalidad de la ley, el caso concreto y los costos que se imponen a aquel que recibe el trato diverso, los que deben resultar tolerables ${ }^{46}$.

La Constitución ha previsto manifestaciones dentro de los derechos constitucionales otras disposiciones referidas a la igualdad. En lo que interesa a este artículo, por tratarse del uso del dominio público conformado por el mar, las playas y los terrenos de playa fiscales aplicado al ejercicio de actividades económicas, debe mencionarse la igualdad ante las cargas públicas del

\footnotetext{
${ }^{43}$ MartíneZ, José Ignacio - ZúñIga Urbina, Francisco, cit. (n. 44), p. 210.

${ }^{44}$ Ibíd., p. 210.

${ }^{45}$ Ibíd., p. 210.

${ }^{46}$ Tribunal Constitucional, sentencia rol $\mathrm{N}^{\circ} 280$ de 1998, considerando $24^{\circ}$;
} considerandos 25|, 35| y 37| de su sentencia rol $N^{\circ} 1535$ de 2009 en que el Tribunal Constitucional resume parte de lo que ha sido su jurisprudencia anterior en la materia. Un estudio particular sobre el principio de igualdad en la jurisprudencia del Tribunal Constitucional en: GALDÁmEZ ZELADA, Liliana, El uso del derecho y jurisprudencia extranjera en los fallos del Tribunal Constitucional de Chile: 2006-2010, en Revista Chilena de Derecho, 39 (Santiago, 2012) 1, pp. 189-223; Correa Sutil, Jorge, Jurisprudencia del Tribunal Constitucional en materia de igualdad ante la ley. ¿ Saliendo de la pura tautologia? En Anuario de Derecho Público de la Universidad Diego Portales (Santiago, 2011), pp. 96-126. 
artículo $19 \mathrm{~N}^{\circ} 20$ y la no discriminación arbitraria en el trato que debe dar el Estado y sus organismos en materia económica.

En el caso de la igualdad ante las cargas públicas y, particularmente ante los tributos, interesa destacar que se autoriza al legislador a utilizar diversos elementos para definir las categorías o tramos de los tributos, mencionando expresamente como parámetros la proporcionalidad de las rentas o la progresión, sin perjuicio de utilizar otros, pero se establece, a su vez, una prohibición vinculada a la razonabilidad como requisito del test de igualdad, referida a que el legislador no puede establecer tributos "manifiestamente desproporcionados o injustos". En este punto ha manifestado el Tribunal Constitucional que un tributo puede ser manifiestamente desproporcionado o injusto "si con su imposición o monto se impide del todo o se limita de tal manera que hace imposible el libre ejercicio de una actividad económica o impide la adquisición del dominio de los bienes a que afecte el impuesto" ${ }^{\prime 7}$.

Finalmente, tratándose de una concesión de uso, el concesionario adquiere un derecho subjetivo, perfecto, para realizar el uso en cuestión ${ }^{48}$. Las concesiones marítimas y de acuicultura otorgan el uso y goce de ciertos bienes nacionales de uso público ubicados en el borde costero, y como tales derechos se constituyen en auténticos bienes incorporales amparados bajo la garantía del derecho de propiedad del artículo $19 \mathrm{~N}^{\circ} 24 \mathrm{CPol}$. Esto obviamente no quiere decir reconocer propiedad sobre los bienes del demanio cuya utilización es amparada por la concesión, sino sobre la concesión misma en cuanto ella consiste en derechos.

\section{ANÁlisis DE LOS REGÍMENES DE LAS CONCESIONES MARÍTIMAS Y DE ACUICULTURA ${ }^{49}$}

El Estado ejerce una labor de ordenación del dominio público que excluye la aplicación del régimen privado, en pos de la consecución de un interés público. Dicho poder de ordenación excede la potestad de policía o vigilancia, pues implica poderes exorbitantes ejercidos en cumplimiento del

${ }^{47}$ Tribunal Constitucional, sentencia rol $\mathrm{N}^{\circ} 203$ de 1994, considerando $9^{\circ}$.

${ }^{48}$ Marienhoff, Miguel, Extinción ("revocación") del permiso de uso especial de bienes integrantes del dominio público, en Anales de la Facultad de Ciencias Jurídicas y Sociales de la Universidad Nacional de La Plata, 32 (Buenos Aires, 1996), p. 15.

${ }^{49}$ Se excluyen del análisis las disposiciones específicas referidas a la acuicultura realizada en centros de cultivo instalados en terrenos privados, que por razones obvias no están incluidas en el régimen concesional. Se excluye, asimismo, toda referencia a la aplicación de las disposiciones sobre concesiones marítimas a la destinación a los servicios públicos de los bienes que se encuentran bajo el control, fiscalización y supervigilancia del Ministerio de Defensa Nacional, a través de la Subsecretaría para las Fuerzas Armadas. 
deber de orientar la acción privada hacia el aprovechamiento de los bienes en la forma útil que ha sido definida por el Estado. De esta forma es que se justifica el otorgamiento de concesiones sobre bienes del demanio para conseguir un interés público, excluyendo el uso común para reemplazarlo por un uso privativo y excluyente.

Las disposiciones sobre concesiones marítimas y de acuicultura serán analizadas en primer lugar en torno a su régimen de protección, lo que comprende las condiciones de acceso, de transferencia y constitución de garantías terceros sobre las concesiones; en segundo lugar en torno a su régimen de uso, que comprende los derechos y las obligaciones que son impuestas al concesionario durante la vigencia de la concesión y a su término. No se aludirá a un régimen de vecindad o cargas que eventualmente deban soportar terceros, debido a que no existen disposiciones específicas de interés para este análisis.

\section{Condiciones de acceso a las concesiones.}

a) Bienes que son objeto de los regímenes concesionales. Las concesiones marítimas son otorgadas en las áreas en que tiene competencia el Ministerio de Defensa Nacional, a través de la Subsecretaría para las Fuerzas Armadas $^{50}$. Corresponde a una facultad privativa de este órgano conceder el uso particular en cualquier forma, de las playas y terrenos de playas fiscales dentro de una faja de 80 metros de ancho medidos desde la línea de más alta marea de la costa del litoral y otorgar concesiones de rocas, fondos de mar, porciones de agua dentro y fuera de las bahías, y en ríos o lagos que sean navegables por buques de más de 100 toneladas, o en los que no siéndolo, siempre que se trate de bienes fiscales, en la extensión en que estén afectados

${ }^{50}$ DFL. N $\mathrm{N}^{\circ}$ 340, de 60, artículo 1: “Al Ministerio de Defensa Nacional, Subsecretaría de Marina, corresponde el control, fiscalización y supervigilancia de toda la costa y mar territorial de la República y de los rios y lagos que son navegables por buques de más de cien toneladas". La Subsecretaría para las Fuerzas Armadas es la sucesora legal de la Subsecretaría de Marina, de conformidad con el artículo 36 de la Ley $\mathrm{N}^{\circ} 20.424$; de ahí que la mención que realiza la LGPA. a la Subsecretaría de Marina debe entenderse hecha a la Subsecretaría para las Fuerzas Armadas. Dicho artículo 36 reza así: " $L a$ Subsecretaria para las Fuerzas Armadas es la sucesora para todos los efectos legales, reglamentarios y contractuales de las Subsecretarias de Guerra, de Marina y de Aviación y de la Dirección Administrativa del Ministerio de Defensa Nacional./ Le corresponderá hacerse cargo de los derechos y obligaciones de los que aquellas fueran titulares y que existieren o se encontraren pendientes a la fecha de entrada en vigencia de esta norma. Toda mención que se haga en leyes, reglamentos y otros instrumentos juridicos respecto de las Subsecretarias de Guerra, de Marina y de Aviación, y de la Dirección Administrativa del Ministerio de Defensa Nacional, se entenderá referida, a partir de esa fecha, a la Subsecretaría para las Fuerzas Armadas. Las facultades de la Subsecretaría de Marina relativas a las concesiones maritimas y acuicolas se entenderán también transferidas a la Subsecretaria para las Fuerzas Armadas". 
por las mareas, de las playas de unos y otros y de los terrenos fiscales riberanos hasta una distancia de 80 metros medidos desde donde comienza la ribera.

Conjuntamente con la dictación de la "Política nacional de uso del borde costero" establecida por Decreto supremo $\mathrm{N}^{\circ}{ }^{\circ} 475$, de 1994 del Ministerio de Defensa Nacional, se creó la Comisión Nacional de Uso del Borde Costero y se fijó entre sus funciones proponer una zonificación de los diversos espacios que conforman el borde costero del litoral, entendiendo por tal, aquella franja del territorio que comprende los terrenos de playa fiscales situados en el litoral, la playa, las bahías, golfos, estrechos y canales interiores, y el mar territorial de la República, que se encuentran sujetos al control, fiscalización y supervigilancia del Ministerio de Defensa Nacional, a través de la Subsecretaría para las Fuerzas Armadas ${ }^{51}$, aunque puede haber reformas $^{52}$. Esto es relevante porque a partir de la creación de la Comisión Nacional, se incentivó a las regiones a crear comisiones regionales que vinieron a asumir el rol de proponer la zonificación del borde costero del litoral regional, así como a emitir pronunciamiento sobre todas las solicitudes de concesiones marítimas que eran presentadas. De este modo, estos órganos de coordinación han venido a ejercer una labor de asesoría al Ministerio de Defensa Nacional, a través de la Subsecretaría para las Fuerzas Armadas, para que éste ejerza la facultad discrecional de otorgamiento de concesiones marítimas atribuida por la normativa pertinente.

El pronunciamiento de las comisiones regionales no es obligatorio en su obtención ni vinculante en su contenido, salvo en el caso de la participación de las comisiones regionales referidas al establecimiento del espacio costero marino de pueblos originarios. En efecto, la comisión nacional y las comisiones regionales de uso del borde costero solo han tenido una existencia

${ }^{51}$ Artículo 2 DS. N ${ }^{\circ}$ 475, de 1995, del Ministerio de Defensa Nacional: Establece la Politica Nacional de Uso del Borde Costero del Litoral y crea Comisión Nacional que indica. Es relevante destacar que la definición de borde costero fija su extensión en el mar territorial y, por ende, el borde costero comprenderá la extensión de 12 millas marinas medidas desde las líneas de base por cuanto, conforme al derecho internacional del mar, es la extensión del mar territorial que Chile ha reclamado para sí como estado ribereño (artículos 2 a 5 de la Convención sobre Derecho del mar o "Convención de Jamaica” de 1982, promulgada por Decreto supremo N 1.393, de 1997, del Ministerio de Relaciones Exteriores).

${ }^{52}$ A la fecha de elaboración del presente artículo se encuentra en primer trámite constitucional en el Congreso Nacional el proyecto de ley, Boletin $\mathrm{N}^{\circ} 8.467-12$, iniciado por "Mensaje" presidencial que modifica la competencia sobre el borde costero del litoral, trasladándola desde el Ministerio de Defensa Nacional al Ministerio de Bienes Nacionales. Dicho proyecto no aborda las diferencias que se ponen de manifiesto en el presente artículo respecto de las concesiones de acuicultura, sino que nuevamente les da un tratamiento absolutamente separado y específico. 
reglamentaria, y en el caso de estas últimas, son constituidas por un acto discrecional del Intendente regional. Solo a partir del año 2008 se da un reconocimiento legal a las comisiones regionales para efectos de participar en la declaración del espacio costero marino de pueblos originarios de conformidad con la Ley $\mathrm{N}^{\circ} 20.249$ y solo acotado a dicho ámbito, en el cual se le otorgan facultades resolutivas y, en consecuencia, el Ministerio de Defensa Nacional, a través de la Subsecretaría para las Fuerzas Armadas, no puede omitir ni desconocer el pronunciamiento de dicha instancia ${ }^{53}$.

Por su parte, conforme al artículo 3 DFL. $\mathrm{N}^{\circ} 340$, de 1960, las concesiones de acuicultura son concesiones marítimas que se rigen por la Ley general de pesca $y$ acuicultura ${ }^{54}$.

Las concesiones de acuicultura pueden ser otorgadas sobre playas de mar, terrenos de playa fiscales, porciones de agua y fondo de mar, en los ríos que sean navegables por buques de más de 100 toneladas de registro grueso y en los ríos que no sean navegables, solo sobre la extensión en que estén afectados por las mareas. En todos los casos, se requiere que dichos bienes hayan sido declarados como áreas apropiadas para la acuicultura mediante decretos expedidos a través del Ministerio de Defensa Nacional ${ }^{55}$. En otras palabras, no basta que estos bienes se encuentren dentro de la competencia del Ministerio de Defensa Nacional, a través de la Subsecretaría para las Fuerzas Armadas, sino que además deben haber sido expresamente declaradas como apropiadas para la acuicultura.

Tales áreas apropiadas no obedecen a un concepto técnico de aptitud para la actividad sino más bien, de conciliación de intereses con otros usuarios del borde costero, ya que la declaración de estas áreas supone descartar todas las áreas que por diversas razones, imponen la preferencia de destino para otros usos, como por ejemplo, la pesca artesanal, el turismo, la conservación de áreas protegidas, entre otros. Para entender este concepto debe señalarse que a la fecha de entrada en vigencia de las disposiciones de la Ley general

${ }^{53}$ Ley N²0.249: Sobre espacios costero marino de pueblos originarios, artículo 2 letra b: "Comisión regional de uso del borde costero o comisión: comisión creada como instancia de coordinación en la aplicación de la politica de uso del borde costero del litoral aprobada por el decreto supremo $N^{\circ} 475$ de 1994 del Ministerio de Defensa Nacional, integrada por representantes de los ministerios y servicios públicos regionales con competencia sobre el borde costero o cuyas funciones tengan incidencia en él, creadas en cada región por el Intendente Regional".

${ }^{54}$ Cabe destacar que la norma presenta en sus incisos $2^{\circ}$ y $3^{\circ}$ definiciones de las concesiones de acuicultura que difieren en su contenido formal, ya que el legislador no realizó la adecuación que se debía al introducir sucesivas modificaciones a este texto legal como resultado de los cambios realizados a la legislación pesquera, específicamente mediante las Leyes $\mathrm{N}^{\text {os }} 18.892$ y 19.079 .

${ }^{55}$ Artículo 67 incisos $1^{\circ}$ y $2^{\circ}$ LGPA. 
de pesca y acuicultura en materia de acuicultura, no se había dictado la "Política nacional de uso del borde costero" ni se habían iniciado los procesos de zonificación del borde costero, los que en la actualidad constituyen una aproximación a un proceso de planificación territorial, en que se efectúa una declaración sobre el uso preferente sobre cada uno de los diversos espacios delimitados del borde costero de una región determinada, y que determinan que la autoridad otorgará las concesiones que sean solicitadas, solo en la medida que ellas tengan por objeto realizar las actividades que sean compatibles con dichos usos.

De esta forma, ante la inexistencia de la zonificación en el año 1991, las áreas apropiadas para la acuicultura fueron el instrumento plasmado en la Ley general de pesca y acuicultura para facilitar el otorgamiento de concesiones evitando conflictos con otros potenciales usuarios de espacios del borde costero en una época en que no existía ningún instrumento con ese mismo objetivo ${ }^{56}$.

Con el surgimiento de la "Política nacional de uso del borde costero del litoral”, se fomentó el establecimiento de zonificaciones del borde costero a nivel regional, dictándose la primera zonificación por Decreto supremo $\mathrm{N}^{\circ} 153$, de 2004, del Ministerio de Defensa Nacional, correspondiente a la región de Aysén. A partir de ese momento surgió el conflicto en la aplicación de dos instrumentos diversos, esto es, las áreas apropiadas para la acuicultura y la zonificación del borde costero, por cuanto no coincidían completamente en torno a las áreas que esta última había determinado como preferentes para la acuicultura. En el año 2010 se introdujo una modificación al artículo 67 LGPA. que indica que cuando exista una zonificación del borde costero regional aprobada por decreto supremo y vigente, las áreas apropiadas deberán compatibilizarse con dicho instrumento, suspendiéndose a partir de la vigencia del decreto respectivo el otorgamiento de concesiones de acuicultura en las áreas declaradas incompatibles con la actividad, de acuerdo con la zonificación del borde costero ${ }^{57}$.

${ }^{56}$ En el año 2010, mediante la Ley $\mathrm{N}^{\circ} 20.434$ se introduce en el artículo $2 \mathrm{~N}^{\circ} 57$ ) de la Ley general de pesca y acuicultura la definición de zonificación del borde costero: "proceso de ordenamiento y planificación de los espacios que conforman el borde costero del litoral, que tiene por objeto definir el territorio y establecer sus múltiples usos, expresados en usos preferentes, los que no serán excluyentes, salvo en los casos que se establezcan incompatibilidades de uso con actividades determinados en sectores delimitados en la misma zonificación y graficados en planos que identifiquen, entre otros aspectos, los límites de extensión, zonificación general y las condiciones y restricciones para su administración, en conformidad con lo dispuesto en la Politica Nacional de uso del Borde Costero establecida en el decreto supremo $(M) N^{\circ} 475$, del Ministerio de Defensa Nacional, de 1995, o la normativa que lo reemplace".

${ }^{57}$ Artículo 67, inciso $12^{\circ}$ LGPA. 
Conforme con lo dicho puede afirmarse que se da una situación de doble regulación para el uso territorial en el caso de la actividad de acuicultura, puesto que las actividades económicas diferentes de la acuicultura que requieren espacios de borde costero para su desarrollo y, por ende, requieren obtener una concesión para su uso y explotación, les basta someterse a la zonificación del borde costero del litoral vigente en la región respectiva y, en los casos en que ella no exista, bastará el pronunciamiento de la comisión regional de uso del borde costero. La actividad de acuicultura, en cambio, requiere someterse a dos regulaciones: las áreas apropiadas para la acuicultura y a la zonificación del borde costero, las que si bien hoy son conciliadas a través del artículo 67 LGPA. que obliga a adecuar las áreas apropiadas a la zonificación del borde costero que se haya dictado, impone un requisito sobreviniente al solicitante que puede llegar a impedir la obtención de la concesión ${ }^{58}$.

Desde el punto de vista de la igualdad constitucional en los términos descritos en V. supra, al incorporarse la zonificación del borde costero en la Ley general de pesca y acuicultura queda abierta la pregunta acerca de la legitimidad de la mantención de las áreas apropiadas para la acuicultura como instrumento. En efecto, se trata de los mismos bienes afectos a las concesiones marítimas y de acuicultura, y existiendo un instrumento como la zonificación del borde costero que asume la misma finalidad de conciliar los intereses de los diversos usuarios, debería encontrarse un elemento objetivo y razonable diverso de los bienes y del conflicto entre diversos usuarios, que justifique un trato diferenciado. Debe desecharse el tipo de actividad económica que se desarrolla, porque en principio, ninguna actividad económica debería tener primacía por sobre otra, dada la regulación constitucional de la libertad de desarrollar cualquier actividad económica del artículo $19 \mathrm{~N}^{\circ} 21 \mathrm{CPol}$. En cuanto a la naturaleza de la actividad económica, podría sostenerse el diverso impacto que la acuicultura genera frente a otras posibles actividades, lo que si bien a priori es un criterio objetivo y podría resultar razonable, no lo es desde el punto de vista de la proporcionalidad, dado que en nuestro sistema institucional el impacto que generan las actividades productivas se evalúan ambientalmente caso a caso.

Puede señalarse que antes de la modificación introducida a la Ley general depesca y acuicultura por la Ley $\mathrm{N}^{\circ} 20.434$ que incorporó la zonificación del borde costero del litoral como instrumento de obligatorio cumplimiento, ella pugnaba directamente con la regulación legal del espacio en que era posible otorgar concesiones de acuicultura, ya que ello no estaba previsto en la

\footnotetext{
${ }^{58}$ De hecho así ha ocurrido con la zonificación del borde costero de la región de Magallanes que se llevó a cabo durante el año 2010 y que implicó la eliminación de un $60 \%$ de las áreas apropiadas para la acuicultura vigentes en la región, con la consiguiente denegación de solicitudes en trámite en dichas áreas.
} 
normativa legal. En tal punto era posible discutir si la solicitud de concesión de acuicultura se encontraba en un área apropiada y no existiendo conflicto de superposición con otra solicitud, el otorgamiento de la concesión era o no discrecional, ya que de ello dependía el efecto que podía otorgarse a la zonificación del borde costero del litoral. En efecto, en tanto se estimara que el otorgamiento de la concesión de acuicultura no era discrecional sino reglada, y sometida en su elemento espacial a las áreas apropiadas para la acuicultura y solo a ellas, la zonificación del borde costero del litoral pugnaba derechamente con la Ley general de pesca y acuicultura. Por el contrario, si el otorgamiento de la concesión de acuicultura era considerado discrecional, la zonificación del borde costero del litoral (instaurada sin una autorización legal expresa y surgida de las facultades de coordinación de la Administración Pública) podía ser aplicada como una forma de dar sustento a la decisión de la Autoridad. Como se dijo supra esto se resolvió a favor de la zonificación en cuanto fue incorporada en la Ley general de pesca y acuicultura, no obstante el conflicto que precedió a tal decisión y que fue planteado inicialmente en la Comisión Nacional de Uso del Borde Costero, cuando la zonificación del borde costero de la región de Aysén se presentó por primera vez para su aprobación y que llevó a que ella fuera aprobada unos años después de su aprobación a nivel regional.

La pregunta sobre la discrecionalidad del otorgamiento de la concesión de acuicultura en materia de su ubicación debe completarse a la luz de los números 21 y 23 del artículo $19 \mathrm{CPol}$. En efecto, si la Constitución asegura el derecho a desarrollar cualquier actividad económica conforme a las normas legales que la regulen y, en el caso de la acuicultura ello ocurre a través de la Ley general de pesca y acuicultura que no contempla discrecionalidad en el otorgamiento de la concesión sino causales regladas de denegación de la misma, no resultaba posible antes y tampoco ahora, sostener la discrecionalidad del otorgamiento.

Lo anterior, porque como se dijo más arriba no se trata que el Estado ejerza facultades de dueño sobre los bienes del demanio, sino que el dominio público importa la instauración de un régimen que permite al Estado intervenir para el cumplimiento de un deber vinculado al cumplimiento de un interés público. Dicho interés se manifiesta en el ordenamiento jurídico y de allí entonces, que no pueda sostenerse la mera discrecionalidad de la Administración en materia de concesiones.

Resulta más complejo sostener este mismo argumento respecto de las concesiones marítimas, debido a que su regulación legal no contempla las causales denegatorias ni un instrumento espacial que determine su otorgamiento, por ende, parece quedar abierto un mayor ámbito de discrecionalidad para la Administración, aun cuando siempre deba fundar razonablemente su 
decisión y sin dar lugar a discriminaciones arbitrarias, en virtud del artículo $19 \mathrm{~N}^{\circ} 2$ CPol. De este modo, resulta más difícil sostener que conforme a la regulación legal vigente, el solicitante de una concesión marítima tiene un derecho a obtener la concesión cuando cumple los requisitos previstos en la ley, porque a diferencia del solicitante de la concesión de acuicultura, en ese ámbito la Administración se ve sometida a las limitaciones generales de la discrecionalidad y no a una regulación específica.

b) Título concesional. La concesión marítima es definida legalmente como aquélla que se otorga sobre bienes nacionales de uso público o bienes fiscales cuyo control, fiscalización y supervigilancia corresponde al Ministerio de Defensa Nacional, a través de la Subsecretaría para las Fuerzas Armadas, cualquiera sea el uso a que se destine la concesión y el lugar en que se encuentren ubicados los bienes ${ }^{59}$. Otra definición es la que señala que la concesión marítima es el acto que, a través del Ministerio de Defensa Nacional, crea derechos a favor de un particular sobre determinados bienes nacionales, otorgándole el derecho de uso y goce por un tiempo definido, producto de un procedimiento que se encuentra reglado, para que el concesionario realice en ellos las actividades de acuerdo al objeto de la concesión, sin menoscabo del bien común ${ }^{60}$.

Se distingue entre concesión marítima "mayor" y "menor" y permisos de escasa importancia. La concesión marítima mayor es aquélla que se otorga por más de 10 años y cuya inversión excede las 2.500 unidades tributarias mensuales; la concesión marítima menor es la que se otorga por más de un año y menos de 10 años y cuya inversión es igual o inferior a 2.500 unidades tributarias mensuales ${ }^{61}$. Además son permisos o autorizaciones las concesiones de escasa importancia y de carácter transitorio y que solo son otorgadas hasta por el plazo de un año ${ }^{62}$.

La concesión de acuicultura es definida como el acto administrativo mediante el cual el Ministerio de Defensa Nacional otorga a una persona los derechos de uso y goce, por el plazo de 25 años renovables sobre determinados bienes nacionales, para que ésta realice en ellos actividades de acuicultura ${ }^{63}$.

Desde el punto de vista del título concesional, la diferencia evidente que surge entre ambos tipos de concesión, es que la de acuicultura tiene un fin muy preciso, el ejercicio de dicha actividad, en tanto, la concesión marítima es el

${ }^{59}$ Artículo 2 DFL. $\mathrm{N}^{\circ}$ 340, de 1960.

${ }^{60}$ Navarrete Tarragó, Arturo, Régimen jurídico de las concesiones maritimas, en Revista Chilena de Derecho, 25 (Santiago, 1998) 4, p. 953.

${ }^{61}$ Artículo 24 letras a) y b) DS. N ${ }^{\circ}$, de 2005.

${ }^{62}$ Artículo 2 del Decreto con fuerza de ley $\mathrm{N}^{\circ} 34$, de 1960.

${ }^{63}$ Artículo $2 \mathrm{~N}^{\circ} 12$ LGPA. Los bienes que son susceptibles de ser otorgados en concesión son los indicados más arriba, en el número 1 a). 
título que se otorga para el uso de los bienes de competencia del Ministerio de Defensa Nacional, a través de la Subsecretaría para las Fuerzas Armadas, no pudiendo especificarse una actividad única por la multiplicidad de usos que ella puede llegar a amparar: muelles, puertos, instalación de tuberías para transporte de diverso tipo de material o la extracción de agua, rampas, etc.

La pregunta que debe plantearse desde el punto de vista de la igualdad es si tales concesiones recaen sobre los mismos bienes; así que ¿es la especificidad de la actividad económica que se habilita la que explica la diferencia de estatuto? En este punto, puede afirmarse que es el tipo de actividad económica que habilita el título concesional el que justifica la existencia de dos regímenes sobre los mismos bienes.

Por su parte, para el ejercicio de la acuicultura se reconoce un solo tipo de concesión, lo que difiere de las concesiones marítimas que regula tres tipos de concesiones dependiendo de la magnitud de la inversión y el tiempo asociado a la actividad que habrá de autorizarse, lo que fundamentalmente se traduce en modificaciones en el procedimiento de tramitación, siendo más simplificado en tanto la concesión solicitada sea de menor duración e inversión. Esto no se prevé para la actividad de acuicultura, aun cuando existen dentro de la actividad diversos tipos de proyectos cuyas diferencias en las magnitudes de inversión requeridas son sustantivas.

La falta de distinción en la tramitación de la concesión de acuicultura dependiendo de la magnitud del proyecto para el cual desea obtenerse una concesión así como la posibilidad de otorgarlas por plazos inferiores, priva a los pequeños acuicultores de un trámite más simplificado que facilite el acceso al título concesional, dando un mismo tratamiento a acuicultores que presentan características manifiestamente diversas. Así por ejemplo, las actividades ejercidas por personas naturales sobre el recurso alga, en sectores cuya superficie no excede de una hectárea, dan cuenta de un segmento de acuicultura de subsistencia, lo que se demuestra por las dificultades históricas que tuvieron para pagar la patente única de acuicultura equivalente a 2 UTM por hectárea anual (hoy cercana a \$ 80.000). Dicho segmento de acuicultores debe someterse a la misma tramitación para obtener la concesión que los proyectos de cultivo de salmones cuyo monto de inversión suele no ser inferior a los dos millones de dólares.

Desde el punto de vista de la igualdad y como se dijo antes, el distinto título concesional se funda en el tipo de actividad económica que se realiza. Sin embargo, no se aprecia un argumento objetivo, razonable y racional por el cual se justifique que no se establezca un procedimiento más simplificado para proyectos de inferior magnitud, por dos razones: en primer lugar, tanto las concesiones marítimas como las de acuicultura recaen sobre la misma clase de bienes, se otorgan por el mismo órgano; y en segundo lugar, porque 
el régimen concesional de acuicultura realiza diferencias de tramitación en materia de evaluación ambiental de proyectos. El distinto tipo de actividad económica no resulta razonable para someter indistintamente a todos los proyectos de acuicultura a un procedimiento que resulta evidentemente mucho más gravoso para cierto grupo de solicitantes.

c) Órgano otorgante. En el caso de las concesiones marítimas, el órgano otorgante es el Ministerio de Defensa Nacional, a través de la Subsecretaría para las Fuerzas Armadas, de conformidad con el artículo 2 DFL. N $^{\circ} 340$, de $1960^{64}$. Si se trata de concesiones de escasa importancia, el órgano otorgante es la Dirección General del Territorio Marítimo.

En el caso de las concesiones de acuicultura, el órgano otorgante es la Subsecretaría para las Fuerzas Armadas del Ministerio de Defensa Nacional, de conformidad con el artículo 80 LGPA ${ }^{65}$. En este caso, tiene una importante intervención en la evaluación técnica de la procedencia de otorgamiento de la concesión la Subsecretaría de Pesca, la que debe aprobar el proyecto técnico de la actividad, conforme al cual se determina específicamente el objeto de la concesión ${ }^{66}$.

d) Sujetos que pueden acceder. No existen normas específicas acerca de quiénes pueden acceder a las concesiones marítimas, por lo que a partir de los requisitos que se exigen para presentar una solicitud simplemente se deduce que las concesiones marítimas pueden ser solicitadas por personas naturales y jurídicas ${ }^{67}$.

En materia de concesiones de acuicultura, la normativa es explícita al señalar que pueden acceder las personas naturales, sean chilenas o extranjeras con permanencia definitiva y las personas jurídicas que sean chilenas constituidas según las leyes patrias. Si la persona jurídica tiene participación de capital extranjero, se debe acreditar que dicha participación ha sido debi-

${ }^{64}$ DFL. N 340, de 1960, artículo 2: "Es facultad privativa del Ministerio de Defensa Nacional, Subsecretaria de Marina, conceder el uso particular en cualquier forma, de las playas y terrenos de playas fiscales dentro de una faja de 80 metros de ancho medidos desde la linea de más alta marea de la costa del litoral; como asimismo la concesión de rocas, fondos de mar, porciones de agua dentro y fuera de las bahias; y también las concesiones en rios o lagos que sean navegables por buques de más de 100 toneladas, o en los que no siéndolo, siempre que se trate de bienes fiscales, en la extensión en que estén afectados por las mareas, de las playas de unos y otros y de los terrenos fiscales riberanos hasta una distancia de 80 metros medidos desde donde comienza la ribera".

${ }^{65}$ Por aplicación del artículo 36 de la Ley N²0.424 como se indicó en la nota 52.

${ }^{66}$ Especies hidrobiológicas a cultivar, límites de producción, estructuras a ser instaladas en los bienes otorgados en concesión, etc.

${ }^{67}$ Artículo 26 DS. N², de 2005. 
damente aprobada en forma previa por el órgano competente para autorizar la inversión extranjera ${ }^{68}$.

Este elemento de los regímenes analizados da cuenta y confirma que lo que justifica los estatutos diferenciados es el tipo de actividad económica, ya que no se regulan categorías de sujetos diversos.

e) Concesiones provisionales. En el caso de las concesiones marítimas es posible autorizar la ocupación anticipada de los sectores solicitados en concesión, mediante el otorgamiento de un permiso transitorio cuyo objetivo será efectuar estudios relacionados con el destino que se pretende dar a dichos sectores, y mientras se tramita el decreto de concesión. El beneficiario del permiso es responsable por los trabajos y de los eventuales daños o perjuicios a terceros, liberándose el Fisco de cualquier responsabilidad. La ocupación anticipada no compromete la decisión del Estado para otorgar o denegar la solicitud de concesión ${ }^{69}$.

En el caso de las concesiones de acuicultura, no existe la figura de las concesiones provisionales, por ende, solo una vez obtenida y entregada la concesión pueden iniciarse los estudios de ingeniería que justifiquen las obras de instalación de las estructuras en donde se desarrollará la actividad de producción de recursos hidrobiológicos, aun cuando ellas no difieren en magnitud de aquéllas que podrían ser objeto de concesiones marítimas. Un elemento interesante de destacar es que antes de la obtención de la concesión se debe obtener el permiso ambiental sectorial de la actividad de acuicultura a realizar, de conformidad con el artículo 87 LGPA, ya sea directamente ante la Subsecretaría de Pesca o a través del Sistema de Evaluación del Impacto Ambiental, dependiendo de la escala y sistema de producción y superficie involucrada en el proyecto. Para tales efectos deben realizarse muestreos en el sector solicitado sin que se encuentre regulado un permiso especial para la extracción de las muestras que exige la normativa, aunque ello puede justificarse por la irrelevancia, en términos de magnitud, de las extracciones que deben realizarse, debiendo perseguirse eventualmente cualquier daño ambiental que se produzca con ocasión de dichas labores mediante la normativa ambiental general.

Nuevamente desde la perspectiva de la igualdad, no encuentra mayor justificación la imposibilidad de otorgar la ocupación anticipada a una concesión de acuicultura para adelantar la realización de estudios relacionados con el destino que se pretende dar a los sectores, como sí ocurre con la concesión marítima. Si el objetivo es la realización de estudios y se hace responsable a quien los realiza de los posibles impactos o daños que de ellos se deriven,

\footnotetext{
${ }^{68}$ Artículo 71 LGPA.

${ }^{69}$ Artículo 5 DS. N ${ }^{\circ}$, de 2005.
} 
no se aprecia la razón por la que en materia de acuicultura se omite dicha posibilidad. ¿Cuál sería la finalidad pública perseguida con esta omisión? Podría señalarse que en el caso de la acuicultura por tratarse de una actividad específica a desarrollar, se reconoce un cierto nivel de potencial daño que podría provocarse y, por ende, se impide el otorgamiento de concesiones provisionales. Parecería que el supuesto de hecho es racional. Sin embargo ¿es razonable? La respuesta es negativa porque se trata de concesiones para estudios; la responsabilidad por daño estaría aparejada al otorgamiento de la concesión provisional y, porque a diferencia de la acuicultura, no se hace un juicio adelantado acerca del impacto potencial de otras actividades económicas que sí pueden acceder a concesiones marítimas.

En consecuencia, ambos regímenes se debiera contemplar tal posibilidad aunque su otorgamiento pueda ser discrecional, atendiendo si la complejidad de la obra a instalar justifica la realización anticipada de estudios. En efecto, porque la instalación de un centro de salmones es de mayor complejidad por el número y magnitud de las instalaciones a utilizar, que la acuicultura sobre algas.

f) Procedimiento de asignación. En el caso de las concesiones marítimas, el procedimiento se inicia con la presentación de la solicitud ante el capitán de puerto del lugar en que se ubique la concesión, la que es objeto de un informe elaborado por la Dirección General del Territorio Marítimo, el que es remitido junto a la solicitud, a la Subsecretaría para las Fuerzas Armadas, la que emite su pronunciamiento al Ministerio de Defensa Nacional, quien en definitiva otorga la concesión ${ }^{70}$.

Ante la competencia entre particulares por el mismo espacio para el otorgamiento de una concesión marítima, se decide a favor de la solicitud que represente mejor el uso previsto para el área, de acuerdo con la zonificación respectiva, conforme con lo establecido en la "Política nacional de uso del borde costero del litoral". Si dos o más solicitudes tienen un mismo objeto, tiene preferencia la que mejor represente alguno de los siguientes factores, en el orden señalado: seguridad nacional, beneficio fiscal, interés social, generación de empleos o divisas. Si las solicitudes tienen iguales o equivalentes beneficios, la preferencia se determinará por la fecha de presentación. A igualdad de todos los factores, resuelve el ministro o el director, según el caso ${ }^{71}$.

En el caso de las concesiones de acuicultura, el procedimiento de asignación consiste en la tramitación de una solicitud que es analizada por diversos órganos del Estado: Servicio Nacional de Pesca en sus instancias

\footnotetext{
${ }^{70}$ Artículo 25 y siguientes DS. N², de 2005.

${ }^{71}$ Artículo 10 DS. $\mathrm{N}^{\circ} 2$, de 2005 ..
} 
local, regional y nacional ${ }^{72}$, Subsecretaría de Pesca ${ }^{73}$, Comisión Regional de Evaluación Ambiental ${ }^{74}$ y Subsecretaría para las Fuerzas Armadas ${ }^{75}$. Ante la competencia por el mismo espacio, se decide a favor de quien presentó antes su solicitud ${ }^{76}$. Es importante destacar el rol de la Subsecretaría de Pesca, la que debe aprobar un proyecto técnico que supone como requisito previo, haber obtenido la resolución de calificación ambiental favorable, en los casos que ello sea procedente. En otras palabras, no puede aprobarse el proyecto técnico, y por ende, no puede dictarse este acto trámite, en tanto no sea obtenida la resolución de calificación ambiental.

No existe una norma que señale de qué forma debería resolverse la competencia por el mismo espacio por parte de un solicitante de una concesión marítima y otro de una concesión de acuicultura. Sin embargo, dado que las concesiones de acuicultura son una especie de concesión marítima, solo cabe concluir que ante dicha situación debieran aplicarse los criterios de decisión

${ }^{72} \mathrm{La}$ función del Servicio (en su instancia local) es elaborar un informe de terreno para verificar la existencia o no de bancos naturales de recursos hidrobiológicos en el sector que se ha solicitado para concesión de acuicultura, de modo de evitar que la eventual concesión pudiese afectarlos. De este modo, se previene el otorgamiento de concesiones de acuicultura sobre este tipo de bancos.

${ }^{73}$ La Subsecretaría de Pesca lleva adelante el análisis cartográfico y técnico de la actividad productiva, por lo que le corresponde aprobar el proyecto técnico de la concesión, acto trámite esencial para el otorgamiento posterior de la misma.

${ }^{74} \mathrm{~A}$ este órgano le corresponde coordinar a los órganos regionales con competencia ambiental para el otorgamiento de la resolución de calificación ambiental al solicitante de una concesión de acuicultura para la operación de un centro de cultivo. Esta resolución constituye un permiso requerido para la mayoría de los proyectos de acuicultura, cuya procedencia depende de la magnitud del proyecto y la superficie a ser dedicada a la actividad, debe ser obtenido en forma previa a la aprobación del proyecto técnico por parte de la Subsecretaría de Pesca. Por último, esta última también participa en la evaluación ambiental como uno de los órganos que tiene entre sus atribuciones el otorgamiento de un permiso ambiental sectorial que debe ser otorgado de conformidad con el artículo 87 de la Ley general de pesca y acuicultura. En los casos en que no procede la obtención de una resolución de calificación ambiental, por no exigirlo así la normativa ambiental, esto es, se trata de un proyecto que no alcanza los niveles del artículo $3^{\circ}$ letra $\mathrm{n}$ ) del Decreto supremo $\mathrm{N}^{\circ} 95$ de 2001, del Ministerio Secretaría General de la Presidencia, el análisis ambiental se realiza en forma sectorial por la Subsecretaría de Pesca directamente, sin la participación de otros órganos.

${ }^{75} \mathrm{El}$ Reglamento sobre otorgamiento de las concesiones de acuicultura fue aprobado por Decreto supremo $\mathrm{N}^{\circ} 290$, de 1993, del Ministerio de Economía, Fomento y Reconstrucción.

${ }^{76}$ Artículo 78 inciso $1^{\circ}$ de la Ley general de pesca y acuicultura en que se señala que dentro del análisis que debe realizarse en cada solicitud, debe determinarse si esta última se sobrepone a otra concesión otorgada o "solicitud en trámite presentada con anterioridad", de donde se deduce que se prefiere a la de fecha anterior. 
indicados más arriba para resolver entre la competencia entre solicitudes de concesiones marítimas.

En cuanto a las diferencias en el procedimiento deben comentarse algunas situaciones. En primer lugar, claramente en el otorgamiento de la concesión de acuicultura no se deja espacio a la decisión discrecional frente a la competencia entre solicitudes, ya que la ley ordena decidir por fecha de presentación, lo que no ocurre con las concesiones marítimas donde los criterios a aplicar implican una apreciación de la Administración, cuya decisión requerirá obviamente una fundamentación objetiva y racional, pero no se somete a una regla única. En segundo lugar, la aprobación del proyecto técnico de acuicultura es un requisito de otorgamiento de la concesión y esto implica la obtención de la resolución de calificación ambiental, en los casos en que ella sea procedente.

En consecuencia, para la obtención de la concesión de acuicultura se exige previamente la calificación ambiental, lo que no es exigible a la concesión marítima. En otras palabras, la concesión que es un título para el uso y explotación de un bien del dominio público y que, por ende, valida el uso privativo y la ocupación de un sector determinado, pero que no prejuzga sobre otros permisos que puedan ser procedentes, en el caso de la acuicultura es exigido como condición de obtención de la concesión. Esto no ocurre con la concesión marítima, ni sobre minas, ni de energía geotérmica, aun cuando por las actividades que ellas amparan se encuentren sometidas igualmente al mencionado trámite. Desde la perspectiva constitucional no se encuentra el fundamento de esta diferencia sustantiva en el tratamiento de la actividad de acuicultura y que aparece claramente como un atentado a la igualdad que se verifica no solo respecto de las concesiones marítimas sino respecto del régimen general de las actividades económicas en materia de obtención del permiso ambiental.

\section{Transferencia de la concesión 77 .}

La concesión marítima puede ser transferida en la medida que sea previamente autorizada la transferencia por decreto del Ministerio de Defensa Nacional y no tiene valor alguno sin este requisito ${ }^{78}$. Para autorizar la transferencia, deben haberse ejecutado las obras comprendidas en ella, estar al día en el pago de la renta y solicitar la autorización al menos 12 meses antes del vencimiento de la concesión ${ }^{79}$.

\footnotetext{
${ }^{77}$ Se excluyen las normas sobre arriendo y cesión de las concesiones por no ofrecer particularidades que pudieran ser interesantes de destacar en forma independiente de la transferencia.

${ }^{78}$ Artículo $6^{\circ}$ DFL. N ${ }^{\circ} 340$, de 1960.

${ }^{79}$ Artículo 41 DS. N², de 2005.
} 
La concesión de acuicultura es transferible sin autorización previa y se exige su registro ante la Subsecretaría para las Fuerzas Armadas para que tenga efectos respecto de terceros, incluida la autoridad ${ }^{80}$.

En cuanto a la forma de llevar a cabo la transferencia, la concesión de acuicultura se transfiere por escritura pública o privada, requiriéndose para que sea oponible a terceros, su inscripción en el registro de concesiones de acuicultura, que lleva la Subsecretaría para las Fuerzas Armadas hasta el 30 de junio de 2013. A partir del 1 de julio de 2013, dicho registro deberá llevarlo la Subsecretaría de Pesca por disposición de la Ley $\mathrm{N}^{\circ} 20.657$, publicada en el Diario Oficial de 9 febrero de 2013. De este modo, la transferencia se perfecciona por un acto entre privados, generando plenos efectos entre las partes, no así ante la Autoridad o terceros en la medida que ella no sea inscrita en el registro de concesiones de acuicultura ${ }^{81}$.

De este modo, una primera diferencia sustantiva entre la transferencia de concesiones marítimas y de acuicultura aparece con ocasión de su perfeccionamiento: en el primer caso requiere autorización previa de la Administración sin la cual no es posible llevarla a efecto; en el segundo, basta la celebración de un acto entre privados, teniendo pleno efecto entre ellos, y para producir efectos respecto de los terceros se requiere inscripción en el registro del acto de transferencia, mediante el cual se constata que ella se ha celebrado dando cumplimiento a los requisitos legales. En todo caso, si

${ }^{80}$ Antes de las modificaciones introducidas a la Ley general de pesca y acuicultura por la Ley $\mathrm{N}^{\circ} 20.657$, existían dos regímenes de transferencia para las concesiones de acuicultura: el del 80 bis y el del 80 ter de la ley. El régimen del artículo 80 bis preveía una situación más ventajosa para aquéllos que habían tramitado su solicitud de concesión pagando una tasa por el trámite respecto de aquéllos que se acogían a una tramitación gratuita y que quedaban acogidos al régimen del 80 ter, fundamentalmente porque se establecían restricciones a la transferencia de la concesión y a la posibilidad de ceder los derechos de operación sobre la concesión. El establecimiento de la diferencia de regímenes de transferencia se debió a las deficiencias constatadas en el sistema de asignación de las concesiones, lo que propició un mercado de solicitudes de concesiones de acuicultura y un aumento de ellas, por lo que se dictó la Ley $\mathrm{N}^{\circ} 20.091$ la que mediante la restricción a la transferencia de concesiones pretendía limitar este mercado de solicitudes y así racionalizar los tiempos de trámite. La instauración de dos regímenes de transferencia no vino a resolver el problema que se trataba de resolver debido a que el sistema de asignación permaneció sin modificaciones y los nuevos requisitos para la transferencia solo vinieron a limitar aún más las posibilidades de acceso a crédito de los pequeños acuicultores. Una crítica a la existencia de estos regímenes de transferencia en IBACACHe, Nelson, Concesiones de acuicultura ¿una reforma inoficiosa? en Revista del abogado, 41 (Santiago, 2007), pp. 15-16.

${ }^{81}$ Artículo 5 LGPA. Esto obedece a una modificación introducida por la Ley $\mathrm{N}^{\circ}$ 20.434 a la ley recién citada. Antes de dicha modificación la transferencia requería previamente la autorización por resolución de la Subsecretaría para las Fuerzas Armadas. 
no se inscribe la transferencia, sus efectos no son oponibles a la Autoridad ni a terceros, siendo procedentes las acciones que correspondan entre las partes por la falta de cambio de titularidad de la concesión en el registro pertinente, ya que conforme a la ley, las obligaciones e infracciones son de cargo del titular o de quien tenga un derecho sobre la concesión que habilite el ejercicio de la actividad, debiendo estarse en todo caso, a la inscripción en el registro de concesiones vigente a la fecha de hacerse exigible la obligación o de la comisión de la infracción ${ }^{82}$.

Desde el punto de vista de la igualdad, la situación de la transferencia entre ambos tipos de concesiones se presenta como compleja. En efecto, entre concesionarios de acuicultura se plantean dos regímenes de transferencia cuya aplicación depende del pago de una tasa de tramitación de la solicitud respectiva. La diferencia de regímenes se traduce en mayores requisitos para proceder a la transferencia. El pago de una tasa de tramitación es un elemento objetivo, sin embargo ¿es razonable para justificar la distinción entre concesionarios de acuicultura? La respuesta es negativa, puesto que quienes tienen menos recursos económicos se ven privados de contar con un régimen más flexible de transferencia, lo que se traduce, asimismo, en un título concesional que reconoce mayores limitaciones.

En la comparación entre la transferencia de concesiones marítimas y de acuicultura se aprecian mecanismos distintos para mantener en manos del Estado el control del tráfico de las concesiones. En el caso de las concesiones marítimas, es una autorización previa; en el caso de las concesiones de acuicultura, es un registro. Puede sostenerse que la transferencia de la concesión marítima importa una mayor complejidad porque implica esperar el otorgamiento de la autorización, cosa que no ocurre con la concesión de acuicultura; sin embargo, la falta de intervención de la autoridad igualmente genera efectos para los particulares, ya que la falta de registro mantiene el acto en el ámbito de un contrato entre privados. En todo caso resulta sui generis este mecanismo, ya que quien ha otorgado la concesión es el Estado y, por esta vía, la decisión de quien es el nuevo concesionario es de un particular.

En la historia fidedigna ${ }^{83}$ de la modificación legal en materia de transferencias en la LGPA consta la intención del legislador de simplificar el trámite, lo que podría considerarse como la finalidad pública que funda la diferencia, dado el plazo excesivo que demoraba la obtención de una concesión. Sin embargo, el efecto en la simplificación es relativo por cuanto si

${ }^{82}$ Artículo 80 inciso $9^{\circ}$ LGPA.

${ }^{83}$ Historia de la Ley $N^{\circ} 20.434$, en Biblioteca del Congreso Nacional, http://www. leychile.cl/Consulta/portada_hl?tipo_norma $=X X 1 \&$ nro_ley $=20434 \&$ anio $=2012$, pp. 13 y 13 [consultada el 30 de octubre de 2012]. 
bien se perfecciona la transferencia por acto entre privados, dando origen a responsabilidad contractual si no se consigue el registro.

\section{Constitución de garantías sobre la concesión.}

No existe dentro de la regulación de las concesiones marítimas, disposición alguna que se refiera a la constitución de garantías sobre la concesión. Tratándose de las normas de derecho público y de bienes cuya administración se encuentra en manos del Estado, se concluye que las concesiones marítimas no son susceptibles de ser entregadas en garantía.

Por su parte, si bien desde el año 1991 la concesión de acuicultura es definida como susceptible de todo negocio jurídico, solo a partir de la Ley $\mathrm{N}^{\circ} 20.434$ del año 2010 se establecen disposiciones específicas referidas a su entrega en garantía ${ }^{84}$. La concesión de acuicultura puede ser objeto de hipoteca, la que salvo específicas disposiciones referidas a su constitución y al efecto de la caducidad de la concesión para el acreedor hipotecario, su regulación se somete al título $38^{\circ}$ del libro IV del Código Civil ${ }^{85}$.

La garantía regulada por la ley es una hipoteca y no una prenda debido a que los bienes otorgados en concesión son inmuebles: terrenos de playa, playa, rocas y porciones de agua y fondo. En este último caso lo que se otorga es el uso de la columna de agua para la instalación de estructuras y dicha columna de agua es fija, pues es un espacio que se define a partir de una superficie determinada por coordenadas geográficas y que se proyecta al fondo marino, por lo que no es mueble como sí lo es el agua. De allí que a pesar que la ley no lo señale, la concesión de acuicultura es un derecho de carácter inmueble, ya que otorga derechos de uso y goce que se ejercen sobre bienes nacionales de uso público que son inmuebles.

$\mathrm{Al}$ no otorgarse la posibilidad de constituir garantías sobre la concesión marítima, puesto que falta una regulación específica y no se declara que ella sea susceptible de negocio jurídico como sí lo hace la regulación de acuicultura y, por el contrario, como se verá más abajo, están sometidas a causales de término discrecionales, trae como consecuencia que el derecho otorgado al concesionario marítimo presente menores posibilidades de actuación que las que tiene un concesionario de acuicultura.

${ }^{84}$ Con anterioridad a la ley 20.434 existieron casos de constitución de prenda industrial sobre concesiones de acuicultura. IBACACHe, Nelson, cit. (n. 83), p. 15. Un estudio sobre la incorporación de esta hipoteca en la LGPA en GUZMÁn BRITO, Alejandro, Dos hipotecas sobre derechos reales administrativos inmuebles: las hipotecas de una concesión de acuicultura y de una concesión de energía geotérmica, en Revista de Derecho de la Pontificia Universidad Católica de Valparaiso, 36 (Valparaíso, primer semestre de 2011), pp. 69-116.

${ }^{85}$ Artículo 81 bis LGPA. 
El concesionario marítimo no tiene la posibilidad de constituir garantías sobre la concesión, circunstancia que lo coloca en una situación desmejorada respecto del concesionario de acuicultura, ya que siendo ambos de títulos concesionales, el segundo trae aparejado mayores beneficios a su titular, lo que es particularmente relevante si se considera que se trata del desarrollo de una actividad económica, donde el Estado no puede otorgar un trato discriminatorio. En efecto, porque si acudimos a lo señalado en materia de fundamento de las facultades del Estado sobre los bienes del demanio, en términos que permitir promover una actividad económica que es deseable en términos de su interés público, resulta plenamente discutible que el Estado tenga menos interés en promover otras actividades sobre el borde costero que la actividad de acuicultura. Lo único claro es la decisión legislativa de favorecer al concesionario de acuicultura.

\section{Derechos y obligaciones del concesionario.}

a) Actividad autorizada sobre el bien concedido. La normativa referida a concesiones marítimas no define un objeto único para este tipo de concesiones ni está referida a un solo tipo de actividad. Por ende, en materia de concesiones marítimas no existe una actividad única que resulta beneficiada por sus disposiciones, sino que se trata de múltiples actividades cuyo elemento común es que ocupan bienes nacionales de uso público y donde pueden instalarse estructuras, realizar obras o construcciones. Así por ejemplo, se requiere una concesión marítima para instalar un muelle, un atracadero de embarcaciones, un puerto, etcétera, siendo en definitiva de distinto tipo las actividades que pueden verse beneficiadas. Por este motivo, el objeto de la concesión, las actividades que ella comprende, y los espacios que se entienden comprendidos en ella, habrán de quedar definidos en el acto concesional, lo que como se verá, tiene también una consecuencia en las causales de término y caducidad de la concesión.

La concesión de acuicultura tiene por único objeto la realización de actividades de cultivo en el área concedida, respecto de la especie o grupo de especies hidrobiológicas incluidas en el acto concesional ${ }^{86}$. Precisamente en virtud de esta declaración expresa de la ley es que resulta criticable la figura creada administrativamente a partir de un dictamen de Contraloría General de la República que reconoce las concesiones de acuicultura "de apoyo" las que no están ni nunca han estado incluidas en la ley ${ }^{88}$ y que consisten en

\footnotetext{
${ }^{86}$ Artículo 69 inciso $1^{\circ}$ LGPA.
}

${ }^{87}$ Dictamen $\mathrm{N}^{\circ} 14.144$, de 10 de mayo de 1995.

${ }^{88}$ Estas figuras corresponden a sectores necesarios para la instalación de recintos en terrenos de playa como bodegas u otros, lo que conforme a la regulación legal debían realizarse mediante la obtención de la correspondiente concesión marítima. Debido 
sectores donde no se ejerce la actividad de cultivo sino que se instalan recintos de apoyo en terrenos de playa.

Agrega la ley que las concesiones de acuicultura no entregan dominio alguno a su titular sobre las aguas ni el fondo marino ubicado en los sectores abarcados por ellas ${ }^{89}$. Esta norma es innecesaria ante la declaración de bienes nacionales de uso público vigente en virtud del CC, las potestades que se establecen a favor del estado en virtud del DFL. $\mathrm{N}^{\circ} 340$, de 1960, del Ministerio de Hacienda sobre concesiones marítimas y la propia naturaleza del acto en virtud del cual se realiza la actividad: una concesión.

La concesión de acuicultura otorga por sí sola a su titular el privilegio de uso exclusivo del fondo correspondiente al área en él proyectada verticalmente por la superficie de la porción de agua concedida ${ }^{90}$. El concesionario puede realizar todas las obras materiales, muelles, atracaderos, inversiones e instalaciones, previa autorización del órgano competente, cuando proceda ${ }^{91}$.

Como puede apreciarse, el régimen de concesiones de acuicultura es absolutamente reglado, atendido su objeto específico, y por ende, ante la falta de regulación de una situación específica que no sea lo referido a derechos y limitaciones del concesionario ${ }^{92}$, deberían aplicarse supletoriamente las normas sobre concesiones marítimas, lo que no ha sido acogido por el órgano contralor que en vez de acudir a las normas sobre concesiones marítimas para resolver la cuestión referida a las instalaciones de apoyo a la acuicultura, ha recurrido a la creación de una figura ad hoc no prevista en la Ley general de pesca y acuicultura.

Este punto es el que resulta mayormente justificado en el tipo de actividad económica que se regula, ya que el distinto tratamiento se impone por el tipo de actividad que se realiza.

a que se otorgan como concesión de acuicultura de apoyo, no reguladas legalmente surgen preguntas como: ¿ son condicionadas a la vigencia de la concesión de acuicultura que apoyan? El régimen de caducidades es reglado y este tipo de concesión no existe; ¿qué tipo de vinculación se exige con la concesión principal: proximidad, proporcional al tamaño de la concesión principal u otra?

${ }^{89}$ Artículo 67 bis LGPA. Esta declaración es inútil desde el punto de vista jurídico, ya que es de la esencia del acto concesional no otorgar la propiedad del bien sobre el que recae, sino sobre los derechos que otorga.

${ }^{90}$ Artículo 74 LGPA.

${ }^{91}$ Artículo 72 LGPA.

${ }^{92}$ Artículo 69 inciso $1^{\circ}$ LGPA: "La concesión de acuicultura tiene por objeto único la realización de actividades de cultivo en el área concedida, respecto de la especies o grupo de especies hidrobiológicas indicadas en la resolución que las otorgan, y permiten a sus titulares el desarrollo de sus actividades, sin más limitaciones que las expresamente establecidas en esta ley y sus reglamentos". 
b) Obligaciones y limitaciones del concesionario. Las obligaciones del concesionario marítimo son:

i) pagar por semestres o anualidades anticipadas una renta mínima de un $16 \%$ anual sobre el valor de tasación de los terrenos, practicada en cada caso por la Inspección de Impuestos Internos correspondiente. Se pueden eximir de este pago a las municipalidades, las instituciones de beneficencia social, de carácter religioso, instrucción gratuita, de deportes, casas del pueblo, etc. pero si se destinan a fines de lucro, se ceden o traspasan a particulares, deberán pagar con efecto retroactivo las rentas mínimas antes señaladas. En los casos en que por el objeto, el fin o forma de la concesión no le sea aplicable la renta señalada y para las concesiones de escasa importancia, se está a lo que dispone el reglamento ${ }^{93}$;

ii) iniciar las obras comprendidas en la concesión o la actividad objeto de ésta, según corresponda, dentro de los 60 días siguientes a la fecha de suscripción del acta de entrega o en el plazo que por motivo fundado, señale el acto administrativo que la otorgó. Las obras o instalaciones deben quedar terminadas en el plazo que indique el decreto que otorgó la concesión ${ }^{94}$;

iii) constituir una garantía a favor del Fisco en caso que la concesión comprenda mejoras fiscales ${ }^{95}$;

$i v)$ constituir una garantía a favor del Fisco en caso que se contemple realizar obras o construcciones en el lugar otorgado en concesión, la que se reemplazará al término de las obras o construcciones por otra garantía equivalente al valor de tasación comercial de las mismas. El objetivo de esta garantía es responder al término de la concesión es cubrir el costo del retiro de las obras o construcciones ${ }^{96}$;

$v)$ retirar las mejoras y construcciones introducidas por el concesionario en el plazo de 90 días contados desde la caducidad o término de la concesión, pasando de lo contrario a beneficio fiscal ${ }^{97}$.

Como limitación del derecho del concesionario marítimo puede mencionarse que la concesión se otorga sin perjuicio de los derechos adquiridos por terceros a cualquier título legítimo ${ }^{98}$.

Por su parte, las obligaciones del concesionario de acuicultura son las siguientes:

i) pagar una patente única de acuicultura, diferenciada, según el tipo de

\footnotetext{
${ }^{93}$ Artículo 4 DFL. N ${ }^{\circ}$ 340, de 1960.

${ }^{94}$ Artículo 9 del DS. N 2 , de 2005.

${ }^{95}$ Artículo 16 del DS. N² 2, de 2005.

${ }^{96}$ Artículo 19 del DS. $\mathrm{N}^{\circ} 2$, de2005.

${ }^{97}$ Artículos 17 y 18 DS. $N^{\circ} 2$, de 2005.

${ }^{98}$ Artículo 5 DFL. N³40, de 1960.
} 
cultivo que se realice ${ }^{99}$, contemplándose una exención por tres años para personas naturales cuya única concesión de algas sea igual o menor a media hectárea y para organizaciones de pescadores artesanales que tengan cualquier tipo de cultivo, siempre que al dividir la superficie total de la concesión por el número de socios, el resultado no exceda de media hectárea;

ii) iniciar operaciones en el plazo de un año contado desde la fecha de la entrega material de la concesión ${ }^{100}$;

iii) no paralizar operaciones por más de dos años consecutivos, salvo que solicite una ampliación de plazo por el equivalente al doble del tiempo de operación que haya antecedido a la paralización, con un máximo de cuatro años ${ }^{101}$;

$i v)$ mantener la limpieza y el equilibrio ecológico de la zona concedida, cuya alteración tenga como causa la actividad acuícola, de conformidad con los reglamentos que se dicten ${ }^{102}$;

v) retirar las mejoras y construcciones introducidas por el concesionario en el plazo de 90 días contados desde la caducidad o término de la concesión, pasando de lo contrario a beneficio fiscal ${ }^{103}$;

vi) responder preferentemente con las obras, instalaciones y mejoras existentes en la concesión si se quedare adeudando al Fisco patentes, rentas, tarifas, indemnizaciones, intereses penales y costas, o cualquier otro derecho establecido por la LGPA y su reglamento ${ }^{104}$.

Las limitaciones del concesionario de acuicultura son éstas:

i) someterse a la producción máxima fijada para el centro de cultivo en la resolución de calificación ambiental ${ }^{105}$;

ii) dar cumplimiento a las medidas coordinadas impuestas por el Servicio

${ }^{99}$ Las concesiones para el cultivo de peces exóticos (salmones) pagan 10 unidades tributarias mensuales por hectárea otorgada en concesión y las concesiones para otro tipo de cultivos es de 2 unidades tributarias mensuales por hectárea otorgada en concesión.

${ }^{100}$ Artículo 69 bis LGPA.

${ }^{101}$ Artículo 69 bis LGPA.

${ }^{102}$ Artículo 74 LGPA. El reglamento que trata esta materia es el ambiental para la acuicultura contenido en el DS. N ${ }^{\circ} 320$, de 2001, del Ministerio de Economía, Fomento y Reconstrucción.

${ }^{103}$ Artículo 73 LGPA.

${ }^{104}$ Artículo 73 LGPA.

${ }^{105}$ El artículo 142 letra e) LGPA no lo dice directamente pero se deduce de la causal de caducidad por no operar en un porcentaje mínimo de la producción comprometida por el centro de cultivo, el que debe ser establecido por un reglamento, el que en todo caso no puede exigir más del $50 \%$ de la producción máxima prevista en la resolución de calificación ambiental del centro de cultivo. 
Nacional de Pesca cuando se haya establecido una agrupación de concesiones ${ }^{106}$;

iii) dar cumplimiento a las medidas de carácter ambiental y sanitario dispuestas en los reglamentos respectivos ${ }^{107}$;

$i v$ ) en el evento de caducidad o término de la concesión, las mejoras y construcciones introducidas por el concesionario quedan a beneficio fiscal cuando ellas estén adheridas permanentemente al suelo y no puedan retiradas sin detrimento de ellas ${ }^{108}$.

En materia de obligaciones se pueden distinguir tres tipos de materias: inicio y ejecución del proyecto para el que se otorgó la concesión; pago de una patente o renta y normas referidas a mejoras y construcciones.

En materia de inicio y ejecución del proyecto, las diferencias en la regulación se fundan más bien en la diversa naturaleza de las actividades, puesto que en las concesiones marítimas se estará a lo que disponga el decreto de concesión, ya que atendido que ella ampara diverso tipo de actividades no puede la normativa prever cada caso concreto, lo que sí puede darse respecto de la concesión de acuicultura donde siempre la actividad consiste en el ejercicio de la acuicultura. Es precisamente en esta materia donde se considera que el régimen diferenciado está fundado constitucionalmente ya que se cumplen las condiciones de objetividad (supuestos de hechos diversos), una finalidad pública, relación coherente entre uno y otro, razonabilidad, racionalidad y proporcionalidad.

En tema de pago de renta o de patente, salvo en el caso de la renta reglada respecto de algunos tipos de concesiones marítimas que están referidas a un porcentaje de su tasación fiscal, en el resto de los casos no se conoce el parámetro utilizado para fijar la renta o tarifa de la concesión marítima o la patente de la concesión de acuicultura. En efecto, si bien tanto para las concesiones marítimas como para las concesiones de acuicultura se establece un monto fijo por superficie, no se relaciona dicho monto a un parámetro objetivo que justifique su monto de la misma forma en uno y otro caso, lo que es particularmente infundado por tratarse de bienes que comparten la misma naturaleza. Más criticable es la situación de las rentas y tarifas de las concesiones marítimas que no estando fijadas en la ley son remitidas a su regulación por el reglamento, no fijando la ley ningún parámetro mínimo

${ }^{106}$ Artículo $2 \mathrm{~N}^{\circ} 52$ ) LGPA. Las agrupaciones de concesiones corresponden a un conjunto de ellas que, en lo fundamental, deben coincidir en un mismo período de descanso de operaciones, esto es, todas las concesiones del área deben paralizar sus operaciones al mismo tiempo como una medida sanitaria y además deben coordinar los tratamientos terapéuticos que son aplicados a las especies en cultivo.

${ }^{107}$ Artículos 86 y 87 LGPA.

${ }^{108}$ Artículo 73 LGPA. 
que deba ser respetado en el ejercicio de la potestad reglamentaria, particularmente tratándose de la fijación de cobro de derechos. Desde el punto de vista constitucional esto es criticable, ya que a pesar de las variaciones que ha tenido el Tribunal Constitucional en materia de remisión normativa que la ley podría realizar al reglamento de ejecución en materia de derechos, incluso para la tesis de la reserva legal relativa en la sentencia rol $\mathrm{N}^{\circ} 480$, el Tribunal plantea la necesidad que la remisión sea determinada, específica, expresamente realizada por la ley y que contenga los elementos esenciales que sean desarrollados por el reglamento. En este caso, este último requisito no concurre.

En cuanto a las mejoras y construcciones, no se exigen garantías al concesionario de acuicultura como sí se exigen al concesionario marítimo, pese a que el primer caso igualmente son realizadas obras que pueden traer aparejado que su retiro implique un costo para el Estado cuando el concesionario las abandone ${ }^{109}$. Conforme lo que se dijo más arriba, en el sentido que el distinto tipo de actividad económica fundaba el distinto trato en materia de obligaciones al inicio y ejecución del proyecto, no se presenta la misma situación en este punto. La mera declaración de que se responderá con las mejoras y construcciones adheridas permanentemente al suelo, constituye una exención arbitraria de una exigencia que está directamente vinculada al interés público. En efecto, porque no existiendo por parte del Estado la posibilidad de reasignar inmediatamente la misma concesión con el mismo objeto, no se aprecia de qué forma el Estado podría obtener de dichas mejoras y construcciones un beneficio de interés público.

Por su parte, no existen diferencias entre ambos tipos de concesiones en cuanto a la obligación de retiro de las obras al término de la actividad.

Finalmente en materia de limitaciones para el concesionario marítimo, ellas no se explicitan en la normativa ya que como se ha dicho supra, las actividades amparadas por la concesión revisten diversa naturaleza por lo cual ellas quedarán consagradas explícitamente en el decreto de concesión y en los casos que procede, por la evaluación ambiental a través del sistema de evaluación ambiental, si procede, dependiendo del tipo y magnitud de la actividad. En el caso de la concesión de acuicultura, en cambio, la actividad importa la necesidad de dar cumplimiento a un estándar ambiental y sanitario, el que se impone mediante una detallada normativa reglamentaria, sometida además a la evaluación ambiental que sea procedente.

\footnotetext{
${ }^{109}$ Muestra de esto fue la crisis generada por la enfermedad que afectó a los salmones provocada por el denominado virus Isa y que implicó el abandono de los centros de cultivo y si bien los concesionarios de acuicultura han regresado paulatinamente a utilizar las instalaciones, la posibilidad de abandono definitivo era cierta, dadas las enormes pérdidas económicas verificadas en esa época.
} 
b) Término de la concesión. La concesión marítima termina por caducidad o por otras causales de término. Son causales de caducidad de la concesión marítima ${ }^{110}$ :

i) el atraso en el pago de la renta de concesión correspondiente a un período anual o a dos períodos semestrales;

ii) la infracción de cualquier disposición del DFL. N³40, de 1960 o de su reglamento; $y$,

iii) el incumplimiento de alguna de las obligaciones establecidas en el decreto de concesión.

Son causales de término de la concesión marítima ${ }^{111}$ :

i) la muerte del concesionario;

ii) el vencimiento del plazo. La concesión marítima puede ser otorgada hasta por un plazo de 50 años ${ }^{112}$;

iii) el término del objetivo para el cual se otorgó;

iv) la destrucción de las mejoras fiscales entregadas en concesión o permiso;

$v$ ) el traspaso o cesión efectuado con consentimiento del Estado;

vi) por acuerdo mutuo del Estado y el concesionario;

vii) por desahucio dado por el Estado al concesionario;

viii) por la terminación de la concesión o del permiso decretada por el Estado.

Respecto de la causal de término indicada en el anterior número viii), se distinguen dos situaciones: el término decretado por el Estado sin responsabilidad para este último, en cuyo caso otorga un plazo de gracia mínimo equivalente a la décima parte del plazo por el cual se otorgó la concesión ${ }^{113} ; \mathrm{y}$, el término decretado por el Estado sin expresión de causa, sin otorgamiento de plazo de gracia pero dando derecho a indemnización de perjuicios a favor del particular afectado ${ }^{114}$. Si bien la primera causal no genera responsabilidad para el Estado, sí genera la necesidad de expresar la causa, puesto que $a$ contrario sensu, la segunda causal indica expresamente que se pone término sin expresión de causa, generando responsabilidad.

Por su parte, la concesión de acuicultura termina por renuncia, caducidad y no renovación.

La renuncia puede ser total o parcial y debe realizarse por escritura pública.

Una reciente modificación efectuada mediante la Ley $\mathrm{N}^{\circ} 20.434$, específicamente el 8 de abril del 2010, impuso un plazo de vigencia a la concesión de

\footnotetext{
${ }^{110}$ Artículo 7 DFL. N 340, de 1960.

${ }^{111}$ Artículo 8 DFL. N 340, de 1960.

${ }^{112}$ Artículo 24 del DS. N² 2 de 2005.

${ }^{113}$ Artículo $9^{\circ}$ DFL. $\mathrm{N}^{\circ} 340$, de 1960.

${ }^{114}$ Artículo 10 DFL. N³40, de 1960.
} 
acuicultura, la que hasta esa fecha tenía carácter indefinido. En consecuencia, hasta el 8 de abril de 2010 las concesiones solo estaban sometidas a causales de caducidad, pero a partir de dicha fecha además se adicionó la no renovación de la concesión, que se verifica en los siguientes casos:

i) si se verifica la condición de haber obtenido la mitad de los informes ambientales negativos en el período ${ }^{115}$;

ii) si no se ha pagado la multa impuesta al titular de la concesión por haber cometido práctica desleal o antisindical o por haber simulado la contratación de trabajadores a través de terceros ${ }^{116}$;

iii) si se han acumulado tres sanciones judiciales ejecutoriadas por prácticas desleales o antisindicales en tres ciclos productivos continuos por hechos acaecidos en un mismo centro de cultivo, respecto de trabajadores del concesionario que hayan prestado sus servicios en el referido centro a la época de ocurrencia de la infracción, incluyendo a los trabajadores a quienes sea aplicable el régimen de subcontratación a que se refiere la Ley $\mathrm{N}^{\circ} 20.123$. Para estos efectos, se contabilizan las sanciones impuestas al titular y sus sucesores cuando ellos sean personas vinculadas conforme al artículo 81 bis LGPA. ${ }^{117}$.

Las causales de caducidad a que se somete la concesión de acuicultura corresponden a un amplio catálogo ${ }^{118}$ :

i) explotar la concesión con un objeto diferente de aquél para el cual se otorgó;

ii) no pagar la patente única de acuiculturaa ${ }^{119}$;

iii) haber sido sancionado o haber sido reiteradamente sancionado en un plazo determinado por infracciones o delitos pesqueros. En el caso de las infracciones incluyen, a los reglamentos de la acuicultura; a la prohibición de enajenación impuesta a las concesiones con régimen de transferencia restringida; por la entrega de información de operación falsa; a la suspensión de operaciones impuesta por razones sanitarias o la reiteración de infracciones sanitarias o ambientales gravísimas;

$i v$ ) no iniciar operaciones dentro del plazo de un año contado desde la entrega de la concesión o paralizarlas por más de dos años consecutivos;

v) fallecimiento del titular si no concurren los herederos con la posesión efectiva a solicitar el cambio de titular en un plazo determinado;

$v i)$ en el caso de los centros de cultivo en lagos, incurrir por tres veces en condición anaeróbica ${ }^{120}$.

\footnotetext{
${ }^{115}$ Artículo 69 inciso $2^{\circ}$ LGPA.

${ }^{116}$ Artículo 84 inciso $9^{\circ}$ LGPA.

${ }^{117}$ Artículo 84 inciso 10 LGPA.

${ }^{118}$ Están contenidas en el artículo 142 LGPA.

${ }^{119}$ Artículo 84 LGPA.

${ }^{120}$ Falta de oxígeno en el fondo del centro de cultivo correspondiente al sector que
} 
En cuanto al término o caducidad de las concesiones marítimas y de acuicultura, como puede apreciarse, se repiten en algunos casos las causales aunque difieren en la figura que ellas hacen procedente. Así, la muerte del concesionario marítimo se contempla como una causal de término, en tanto se prevé como una causal de caducidad en el caso de la concesión de acuicultura, contemplándose en ambos casos la posibilidad de transmisión del derecho a los herederos cuando comparezcan ante la Autoridad con la posesión efectiva en determinado plazo.

Por lo que atañe al plazo, la concesión marítima puede ser otorgada hasta por un plazo de 50 años, en tanto la de acuicultura solo puede serlo hasta por un plazo de 25 años, previéndose en todo caso la renovación por el mismo plazo si no se verifican las causales de no renovación. Si bien la no renovación por causa ambiental no reviste mayores comentarios, dado que resulta equivalente al cumplimiento de las obligaciones del concesionario marítimo cuya infracción acarrea su término, en el caso de la concesión de acuicultura aparecen dos causales de no renovación que escapan a la relación concesionario-Estado y que se deriva de la relación empleador-trabajador. En efecto, como se plantea supra, y aunque puede discutirse la real posibilidad de aplicación de esta norma, el no pago de una multa o la acumulación de sanciones por infracciones laborales implican la no renovación de la concesión, lo que no aparece en el caso de la concesión marítima. De este modo, se imponen gravosas consecuencias por la comisión de infracciones que no se vinculan directamente con el ejercicio de la actividad y somete al concesionario de acuicultura a un tipo de sanción, la no renovación, que no se prevé para las concesiones marítimas, ni para otro tipo de regímenes concesionales. En este caso, ni siquiera se encuentra el supuesto de hecho que funde el trato diferenciado más perjudicial para el concesionario de acuicultura respecto de los demás concesionarios administrativos, no sólo de las concesiones marítimas y, por ende, se trata de una norma abiertamente inconstitucional.

Cabe destacar que el legislador ha tenido especial interés en incorporar este tipo de causales en la regulación de la Ley general de pesca y acuicultura, dado que en su última modificación efectuada por la Ley $\mathrm{N}^{\circ} 20.657$, se incorpora como causal de no renovación de las licencias de pesca que crea la ley para los actuales armadores industriales.

Otra situación que merece ser destacada es la posibilidad que se otorga al Estado para dar término a una concesión marítima de dos formas: con expresión de causa, plazo de gracia pero sin derecho a indemnización o sin expresión de causa, sin plazo de gracia pero con derecho a indemnización.

se encuentra debajo de las balsas jaulas o estructuras en que se encuentran los peces en cultivo. 
Cabe cuestionar constitucionalmente la privación del derecho del concesionario sin responsabilidad para el Estado aun cuando así lo disponga la normativa pertinente, ya que el DFL. $\mathrm{N}^{\circ} 340$, de 1960 es una normativa previa a la Constitución de 1980 y, por ende, debiera estimarse derogada tácitamente en este punto por atentar contra el derecho de propiedad sobre el bien incorporal de que es titular el concesionario marítimo (derecho real administrativo), que como se puso de manifiesto más arriba es reconocida por el Tribunal Constitucional como una garantía a favor de los concesionarios administrativos. En consecuencia, aceptado que se está privando de un bien protegido por propiedad y aún cuando la causal de término anticipado esté fundada en la función social, la igualdad ante las cargas públicas del artículo $19 \mathrm{~N}^{\circ} 20$ CPol. lleva a considerar una indemnización, ya que si el Estado en ejercicio de sus potestades exorbitantes en relación al dominio público decide, en pos del interés público poner término anticipado a una concesión marítima, deberá indemnizar dicho daño patrimonial que no debe ser soportado por el concesionario.

Las posibilidades de término recién comentadas, no aparecen en el caso de concesión de acuicultura, no contemplándose fórmula alguna para darle término anticipado a una concesión si no es por la concurrencia de una causal de caducidad, lo que aparece actualmente morigerado por la imposición de un plazo a la concesión en reemplazo de su anterior condición de indefinida, pero que plantea la pregunta acerca de la fórmula que debería emplearse para revertir dicho tipo de concesiones a favor del Estado, cuando así lo haga recomendable el interés público.

Las causales de caducidad, tanto de la concesión marítima como de la concesión de acuicultura, se relacionan directamente con el incumplimiento de las obligaciones contenidas en la normativa que las rige o del proyecto aprobado, por ende, se configuran como consecuencias necesarias de las obligaciones y derechos correlativos previstos en atención a la actividad económica específica que cada una de ellas amparan.

\section{CONCLUSIONES}

$1^{\circ}$ La potestad del Estado sobre los bienes del dominio público se concreta en la ordenación del aprovechamiento de dichos bienes, los que se extraen del tráfico privado y, en muchos casos, se extraen también del uso común, a fin de asegurar, conforme al ordenamiento jurídico, la consecución de un interés público. Por ende, no se da solo un régimen exorbitante de atribuciones al Estado sino que ellas están derechamente orientadas al cumplimiento de un deber impuesto a la Autoridad, conforme a la ley y al objetivo que habrá de ser satisfecho. 
$2^{\circ}$ Considerando lo anterior, la regulación del aprovechamiento de los bienes del dominio público debe ser analizada a la luz de las normas constitucionales, restringiéndose de este modo la supuesta discrecionalidad de la autoridad en torno a su administración. Así las cosas, en cuanto las concesiones están vinculadas al ejercicio de actividades económicas, su regulación forma parte de la normativa a las que debe someterse el particular $y$, por ende, su aplicación no admite un amplio espacio para el ejercicio de la discrecionalidad administrativa.

$3^{\circ}$ En primer lugar, cabe considerar que las concesiones marítimas y de acuicultura en cuanto recaen sobre bienes nacionales de uso público, han sido colocados en un régimen excepcional para la consecución de un interés público (artículo $19 \mathrm{~N}^{\circ} 23 \mathrm{CPol}$.). En segundo lugar, la concesión otorga un derecho real administrativo que diferencia de los bienes sobre los que recae, admite en general todo tipo de negocio jurídico y se encuentra amparado por el derecho de propiedad.

$4^{\circ} \mathrm{La}$ igualdad y la no discriminación arbitraria importa la necesidad de fundar los diferentes estatutos concesionales en base a un supuesto de hecho (objetividad), una finalidad de interés público, una relación coherente entre el supuesto y la finalidad donde se cumplan las condiciones de racionalidad, razonabilidad y proporcionalidad, particularmente cuando ellos recaen sobre la misma clase de bienes como es el caso de las concesiones marítimas y de acuicultura.

$5^{\circ}$ Las concesiones marítimas y de acuicultura son otorgadas sobre la misma clase de bienes por lo cual este elemento no constituye un elemento objetivo que justifique las diferencias de estatuto. En consecuencia, siendo además la misma autoridad otorgante, el procedimiento y el título concesional no debieran presentar mayores diferencias como las constatadas en materia de procedimiento de otorgamiento, transferencia, constitución de garantías sobre ellas, concesiones provisionales y renovación de la concesión. Sí, en cambio, el tipo de actividad amparada por las concesiones marítimas y de acuicultura aparece como elemento objetivo, racional y razonable apto para fundar constitucionalmente las diferencias, las que se manifiestan particularmente en la normativa más flexible para amparar mayor cantidad y diversidad de actividades en el caso de las concesiones marítimas por no estar referidas a un catálogo único, específico y más detallado en el caso de las concesiones de acuicultura. Aparece entonces cumplido el requisito de la proporcionalidad, en el sentido que el medio y la finalidad resultan coherentes sin resultar especialmente gravoso o beneficioso para una de las categorías de concesionarios. Así también aparecen justificadas las diferencias que se pusieron de manifiesto en materia de obligaciones y limitaciones del 
concesionario durante el ejercicio de la actividad (lo que hemos llamado el régimen de uso) y al término de ellas.

$6^{\circ}$ Finalmente, y desde la perspectiva de conciliar el interés público inserto en los bienes del dominio público (que ha llevado a declarar tales bienes como nacionales de uso público en virtud del artículo $19 \mathrm{~N}^{\circ} 23 \mathrm{CPol}$.), la necesidad de certeza y el respeto al derecho de propiedad del concesionario, se aprecia la falta de una regulación específica del término anticipado de las concesiones marítimas y de acuicultura que permita al Estado recuperar un bien nacional de uso público ante situaciones fundadas y excepcionales que así lo justifiquen, pagando la correspondiente indemnización de conformidad con el artículo $19 \mathrm{~N}^{\circ} 24$ inciso $3^{\circ} \mathrm{CPol}$. En el caso de las concesiones marítimas y habiéndose previsto el término anticipado, podría fundarse la indemnización en los casos en que la norma respectiva no la hace procedente en virtud de la igualdad ante las cargas públicas del artículo $19 \mathrm{~N}^{\circ} 20 \mathrm{CPol}$.

\section{BIBLIOGRAFÍA}

Aldunate Lizana, Eduardo, Limitación y expropiación: Scilla y Caribdis de la dogmática constitucional de la propiedad, en Revista Chilena de Derecho, 33 (Santiago, 2006) 2.

BARbosa Rebolledo, Gonzalo, Concesiones maritimas (seminario de titulación para optar al grado de Licenciado en la Facultad de Ciencias Jurídicas y Sociales de la Universidad de Concepción, Concepción, 1987).

Bermúdez Soto, Jorge, Derecho administrativo general (2a edición, Santiago, ThomsonReuters, 2011).

Bon, Pierre, El dominio público ante el derecho administrativo francés, en Revista Chilena de Derecho, 25 (Santiago, abril-junio 1998) 2.

Cea Egaña, José Luis, Informe en Derecho: Variación del estatuto del dominio sobre concesiones de radiodifusión televisiva, en Revista Chilena de Derecho, 18 (Santiago, 1991) 3.

Celaya Bastidas, Rodolfo, Naturaleza jurídica del permiso de emisión transable, en Revista Chilena de Derecho, 28 (Santiago, 2002) 2.

Correa SUTIL, Jorge, Jurisprudencia del Tribunal Constitucional en materia de igualdad ante la ley. ¿Saliendo de la pura tautología? En Anuario de Derecho Público de la Universidad Diego Portales (Santiago, 2011).

FonT i Llovet, Tomás, La protección del dominio público en la formación del derecho administrativo español: potestad sancionadora y resarcimiento de daños, en Revista de Administración Pública, 123 (Madrid, septiembre-diciembre 1990).

Galdámez Zelada, Liliana, El uso del derecho y jurisprudencia extranjera en los fallos del Tribunal Constitucional de Chile: 2006-2010, en Revista Chilena de Derecho, 39 (Santiago, 2012) 1.

GARCía PÉrez, Marta, La naturaleza jurídica de la autorización y la concesión, a propósito de la utilización del dominio público, en Anuario de la Facultad de Derecho de la Universidad de La Coruña, 1 (Galicia, 1997). 
González Vergara, Ariel, La concesión, acto administrativo creador de Derechos (Santiago, 1965).

GuZmán Brito, Alejandro, Dos hipotecas sobre derechos reales administrativos inmuebles: las hipotecas de una concesión de acuicultura y de una concesión de energía geotérmica, en Revista de Derecho de la Pontificia Universidad Católica de Valparaíso, 36 (Valparaíso, primer semestre de 2011).

Historia de la Ley $\mathrm{N}^{\circ} 20.434$, en Biblioteca del Congreso Nacional, http://www.leychile. cl/Consulta/portada_hl?tipo_norma $=X X 1 \&$ nro_ley $=20434 \&$ anio $=2012$.

Marienhoff, Miguel, Extinción ("revocación") del permiso de uso especial de bienes integrantes del dominio público, en Anales de la Facultad de Ciencias Juridicas y Sociales de la Universidad Nacional de La Plata, 32 (Buenos Aires, 1996).

MartíneZ, José Ignacio - ZúÑIga Urbina, Francisco, El principio de razonabilidad en la jurisprudencia del Tribunal Constitucional, en Estudios Constitucionales, 9 (Talca, 2011) 1 .

Montt Oyarzún, Santiago, El dominio público (Santiago, 2002).

Navarrete Tarragó, Arturo, Régimen jurídico de las concesiones maritimas, en Revista Chilena de Derecho, 25 (Santiago, 1998) 4.

Parejo Alfonso, Luciano, Dominio público: un ensayo de reconstrucción de su teoría general, en Revista de Administración Pública, 3 (Madrid, enero-diciembre 1983) 100-102.

Parejo Alfonso, Luciano, Reconstrucción de una teoría general del dominio público, en Anuario Facultad de Ciencias Jurídicas Universidad de Antofagasta, 7 (Antofagasta, 2001).

Rabossi, Eduardo, El principio de igualdad y la discriminación, en Revista del Centro de Estudios Constitucionales, 7 (Madrid, 1990).

Sayagués Laso, Enrique, Tratado de Derecho administrativo (Montevideo, 1959), I.

Silva Cimma, Enrique, Derecho administrativo chileno y comparado. Actos, contratos y Bienes (Santiago, Editorial Jurídica de Chile, 1995, reimp. 2001).

Vergara Blanco, Alejandro, Concesiones de dominio público y caracterización de las concesiones mineras, en Revista Chilena de Derecho, 16 (Santiago, 1989) 3.

ZúNíga Urbina, Francisco, Constitución y dominio público (dominio público de minas y aguas terrestres, en Ius et Praxis, 11 (Talca, 2005) 2. 